Article

\title{
Effect of Functional Group on the Catalytic Activity of Lipase B from Candida antarctica Immobilized in a Silica-Reinforced Pluronic F127/ $\alpha$-Cyclodextrin Hydrogel
}

\author{
Cédric Decarpigny, Anne Ponchel (D), Eric Monflier (D) and Rudina Bleta *(D) \\ University of Artois, CNRS, Centrale Lille, ENSCL, Univ. Lille, UMR 8181-UCCS-Unité de Catalyse et Chimie du \\ Solide, F-62300 Lens, France; cedric.decarpigny@univ-artois.fr (C.D.); anne.ponchel@univ-artois.fr (A.P.); \\ eric.monflier@univ-artois.fr (E.M.) \\ * Correspondence: rudina.bleta@univ-artois.fr; Tel.: +33-3-2179-1740
}

check for updates

Citation: Decarpigny, C.; Ponchel, A.; Monflier, E.; Bleta, R. Effect of Functional Group on the Catalytic Activity of Lipase B from Candida antarctica Immobilized in a Silica-Reinforced Pluronic F127 / $\alpha$-Cyclodextrin Hydrogel. Gels 2022, 8, 3. https://doi.org/ $10.3390 /$ gels 8010003

Academic Editors: Thomas B. H. Schroeder, Ximin He and Yi Cao

Received: 10 November 2021 Accepted: 16 December 2021 Published: 21 December 2021

Publisher's Note: MDPI stays neutral with regard to jurisdictional claims in published maps and institutional affiliations.

Copyright: (C) 2021 by the authors. Licensee MDPI, Basel, Switzerland. This article is an open access article distributed under the terms and conditions of the Creative Commons Attribution (CC BY) license (https:// creativecommons.org/licenses/by/ $4.0 /)$.

\begin{abstract}
Surface modification plays a key role in the fabrication of highly active and stable enzymatic nanoreactors. In this study, we report for the first time the effect of various functional groups (epoxy, amine, trimethyl, and hexadecyl) on the catalytic performance of lipase B from Candida antarctica (CALB) incorporated within a monolithic supramolecular hydrogel with multiscale pore architecture. The supramolecular hydrogel formed by host-guest interactions between $\alpha$-cyclodextrin $(\alpha-C D)$ and Pluronic F127 was first silicified to provide a hierarchically porous material whose surface was further modified with different organosilanes permitting both covalent anchoring and interfacial activation of CALB. The catalytic activity of nanoreactors was evaluated in the liquid phase cascade oxidation of 2,5-diformylfuran (DFF) to 2,5-furandicarboxylic acid (FDCA) under mild conditions. Results showed that high FDCA yields and high efficiency conversion of DFF could be correlated with the ability of epoxy and amine moieties to keep CALB attached to the carrier, while the trimethyl and hexadecyl groups could provide a suitable hydrophobic-hydrophilic interface for the interfacial activation of lipase. Cationic cross-linked $\beta-C D$ was also evaluated as an enzyme-stabilizing agent and was found to provide beneficial effects in the operational stability of the biocatalyst. These supramolecular silicified hydrogel monoliths with hierarchical porosity may be used as promising nanoreactors to provide easier enzyme recovery in other biocatalytic continuous flow processes.
\end{abstract}

Keywords: CALB; supramolecular hydrogel; silica; surface functionalization; $\alpha$-cyclodextrin; Pluronic F127; 2,5-furandicarboxylic acid

\section{Introduction}

In the current context where plastic pollution is becoming a source of increasing concern and a pressing environmental issue, the development of new ecofriendly catalytic processes for the conversion of renewable biomass into high value biodegradable materials represents a major challenge for sustainable development [1-5]. In particular, bioplastics are currently experiencing a strong development with a global production of 2.11 million tons in 2020, which is set to increase to approximately 2.87 million tons in 2025 [6].

2,5-Furandicarboxylic acid (FDCA), obtained from 5-hydroxymethylfurfural (HMF) oxidation, is a key building block for the production of bio-based polymers, such as polyamides and polyesters, and has recently been identified as a potential substitute of petroleum-based terephthalic acid (TPA), the main building block of polyethylene terephthalate (PET) used in food packaging and plastic bottles [7]. Polyethylene furanoate (PEF) produced by polycondensation of ethylene glycol and FDCA, has demonstrated superior barrier and thermal properties with respect to PET, and is expected to enter the market very soon, in the early 2023 [6].

To date, various metal-based catalysts such as gold, platinum, and palladium nanoparticles, as well as mixed oxides, have been used as heterogeneous catalysts for the production of FDCA [8]. However, those catalysts require high temperatures and pressures, as well as 
strongly alkaline conditions that tend to produce large amounts of salts, thus limiting the development of the process on a large scale [9].

To help meet growing demands for green and sustainable chemicals, biocatalysis has emerged as a promising technology over the past twenty years [10-12]. Enzymes are particularly suitable biocatalysts for biomass conversion as they operate under eco-friendly conditions (moderate temperature, atmospheric pressure, and physiological $\mathrm{pH}$ ) and exhibit excellent selectivity (regio-, chemo-, and enantio-), thus reducing the formation of by-products [13-16]. Nevertheless, despite the recent progress in biomolecular engineering, the industrial applications of enzymes have been hampered by a poor long-term stability and difficulties in recycling the biocatalyst. To overcome those limitations, immobilization of enzymes on a solid carrier is a promising technology to increase their operational stability for reuse in several cycles, thus reducing the biocatalyst cost [10].

Hydrogels are three-dimensional macromolecular networks composed of hydrophilic polymers interconnected trough physical or chemical nodes [17]. The macromolecular network can incorporate large amounts of water, generally more than $80 \%$ of the total mass, conferring to the hydrogel biocompatibility properties [18]. Unlike synthetic hydrogels, supramolecular hydrogels are reversible in nature because the crosslinking nodes are formed by non-covalent bonds [19]. The first cyclodextrin (CD)-based supramolecular hydrogels reported in the literature are those formed between poly (ethylene glycol) (PEG) and $\alpha$-CD [20]. Threading of several $\alpha$-CDs along the chain of a high molecular weight PEG $(>10,000 \mathrm{Da})$ was shown to cause the formation of insoluble polypseudorotaxanes that tended to self-assemble into three-dimensional organized supramolecular nanostructures [21].

In the case of nonionic Pluronic PEO-PPO-PEO triblock copolymers, where thinner PEO blocks flank the middle PPO block, it has been shown that $\beta$-CD slides along the hydrophilic PEO blocks to selectively thread the middle hydrophobic PPO blocks, while $\alpha$-CD selectively threads the flanking PPO blocks forming polypseudorotaxanes in high yields [22]. As demonstrated by Travelet et al. [23,24], the growth of columnar nanocrystallites resulting from the self-organization of several polypseudorotaxanes is believed to play a key role in maintaining the hydrogel in a stable water-swollen state.

The ability of hydrogels to incorporate high levels of proteins, cells, antibodies, peptides, and genes has been widely described in the literature, especially for biomedical applications [25-27]. Importantly, the interconnected three-dimensional structure of supramolecular PEG / $\alpha$-CDs hydrogels [28] can provide a favorable microenvironment for the incorporation of biomolecules, in particular enzymes [29]. However, under acidic conditions [30], or in the presence of molecules comprising acidic functions, such as the FDCA, these hydrogels suffer from lack of stability due to the unthreading of $\alpha$-CD from the polymer chain, thus resulting in partial dissolution of the interconnected 3D structure and further release of the biocatalyst. To overcome those limitations, solidification of the supramolecular hydrogel network through silicification is a versatile strategy for enhancing the biocatalyst stability and improving its catalytic performance. Indeed, surface silanols can be further functionalized with various chemically reactive and hydrophobic groups, permitting effective covalent anchoring and interfacial activation of lipases. Nevertheless, in the specific case of $\alpha$-CD-based hydrogels, the intercalation of silica layers with the polypseudorotaxanes, as well as the presence of a thick hydration shell on the hydrogel surface, may hinder the accessibility of surface silanols to the silylating agent, thus making surface functionalization challenging.

To date, the functionalization of silicified hydrogels has not been thoroughly investigated and little work has been done on their use as host matrices for the immobilization of enzymes for catalytic applications $[29,31]$. However, these hybrid systems could provide an interesting alternative to mesoporous silicas, such as MCM-41 [32] or SBA-15 [33], owing to their tunable surface properties, hierarchical pore structure, and promising mechanical properties [34,35]. 
Herein, we present a new approach that combines the concepts of supramolecular chemistry and sol-gel process, together with surface functionalization, to develop hierarchically porous monoliths able to incorporate high amounts of Candida antarctica lipase B (CALB). CALB has previously been identified as one of the most important lipases in industrial applications owing to its high selectivity toward secondary amines and secondary alcohols [36,37], as well as its high resistance toward $\mathrm{H}_{2} \mathrm{O}_{2}$ [38,39]. Prior to CALB immobilization, we have investigated the effect of a wide variety of organosilanes on the surface properties of the silicified hydrogel. To highlight the advantages and limitations of different functional groups, the catalytic performance of nanoreactors was evaluated in the liquid phase oxidation of 2,5-diformylfuran (DFF) to FDCA. In addition to the effect of reactive and hydrophobic groups, the impact of cationic cross-linked $\beta-C D$ as an enzyme-stabilizing agent was also examined.

\section{Results}

\subsection{Silicification of the Pluronic F127/ $\alpha-C D$ Hydrogel}

A hierarchically porous hybrid material was prepared using the Pluronic F127 / $\alpha-C D$ hydrogel as template and tetramethoxysilane (TMOS) as silica source (Figure 1A) [31]. First, host-guest interactions between poly (ethylene oxide) (PEO) blocks of F127 and $\alpha-C D$ in aqueous phase led to total dissociation of the micelles. Then, the self-assembly of polypseudorotaxanes resulted in a physically cross-linked hydrogel and its further silicification through hydrolysis and condensation of TMOS yielded a three-dimensional silica-reinforced network containing a thin layer of hydrogel. Pristine hydrogel displayed a thixotropic behavior forming a stable gel structure at rest (Figure 1B), but becoming fluid when agitated. Moreover, the thixotropic degree became more pronounced with increasing the polymer loading (Figure S1, ESI). Optical microscopy images in polarized light showed weak birefringence textures developed by nanocrystallites within pristine hydrogel (Figure 1C), while addition of TMOS greatly accelerated their growth (Figure 1D). After annealing at $60^{\circ} \mathrm{C}$ for $48 \mathrm{~h}$, followed by excess template removal, the mixture solidified into a porous monolith (Figure 1E). SEM images indicated formation of structures with flower-like patterns (Figure 1F) made-up of petals with 40-50 nm thickness (Figure 1G), while TEM micrographs revealed that the pore wall was comprised of particles with fibberlike morphology, consistent with the elongated cylindrical structure of polypseudorotaxanes (Figure $1 \mathrm{H}$ ). The surface area and pore volume determined by $\mathrm{N}_{2}$-adsorption analysis (Figure 1I) were $267 \mathrm{~m}^{2} / \mathrm{g}$ and $0.542 \mathrm{~cm}^{3} / \mathrm{g}$ respectively, while mesopores had average $3.6 \mathrm{~nm}$ and $8.1 \mathrm{~nm}$ diameters originating from individual polypseudorotaxanes and channellike nanocrystallites respectively (Figure 1I, inset). 

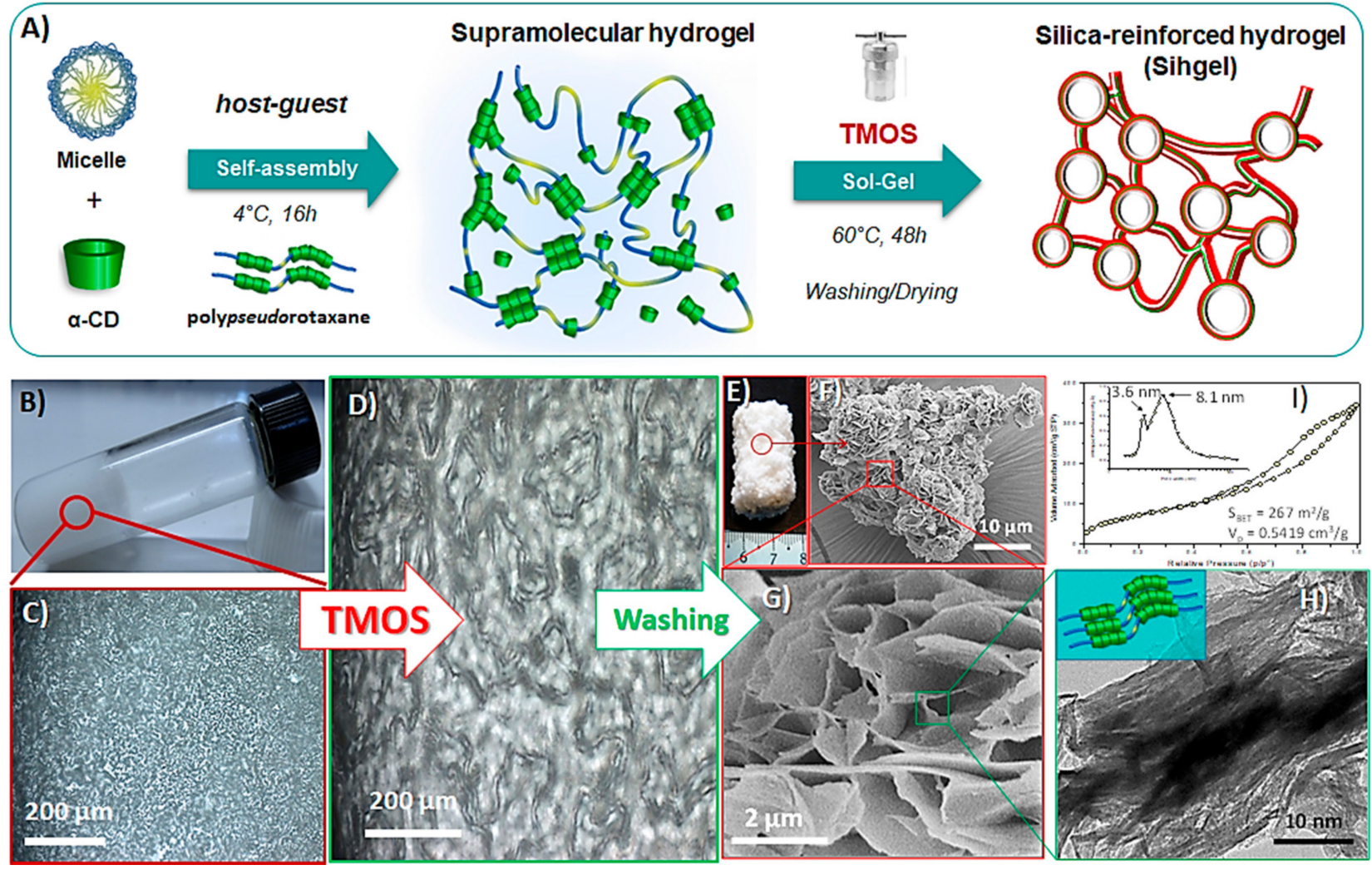

Figure 1. Schematic illustration of the procedure used for the preparation of silica-reinforced Pluronic F127 / $\alpha$ CD hydrogel (A). Visual aspect of the supramolecular hydrogel (B). Polarized optical microscopy images of the hydrogel before (C) and after silicification (D) showing birefringent textures. Visual aspect of the porous monolith after annealing at $60{ }^{\circ} \mathrm{C}$ and removal of the excess of template (E). SEM $(\mathbf{F}, \mathbf{G})$ and TEM $(\mathbf{H})$ micrographs of the silicified hydrogel and corresponding $\mathrm{N}_{2}$ adsorption results $(\mathbf{I})$.

\subsection{Effect of Functionnal Groups}

\subsubsection{Method for Surface Functionalization and Immobilization of CALB}

Prior to enzyme immobilization, the surface of silica-reinforced hydrogel was modified with different functional groups from four organosilanes (Figure 2). (3-glycidoxypropyltrimethoxysilane (GPTMS) and 3-aminopropyl trimethoxysilane (APTMS) were used as chemically reactive groups for the covalent binding of CALB, while chlorotrimethylsilane (CTMS) and hexadecyltrimethoxysilane (HDTMS) were employed as hydrophobic functions for its interfacial activation.

Surface modification with GPTMS (Figure 2(a1)) produces a terminal epoxy group which further reacts with the nucleophilic primary amines of lysine residues on CALB surface through a ring opening reaction, yielding a secondary amine [40]. Owing to its high reactivity, the epoxy group can also react with other nucleophiles, such as the hydroxy groups available on the hydrogel surface and the thiol moieties present on the cysteine residues of the enzyme. As the ring opening reaction with primary amines is usually reported to be more favorable under neutral or moderate alkaline conditions [41], grafting of CALB was carried out in phosphate buffer at $\mathrm{pH} 7.5$.

Conversely, the rate at which the imine bond forms has been reported to be greatest near a $\mathrm{pH}$ of 5.0 [42]. Therefore, after surface functionalization with aminopropyl groups from APTMS, the reaction with the bifunctional spacer, i.e., the glutaraldehyde (GAH) or the glutaric anhydride (GAC) was carried out in acetate buffer ( $\mathrm{pH}$ 4.6) (Figure 2(a2)) GAH provides an aldehyde group that reacts with the primary amine of lysine providing 
an imine bond (Schiff base) (Figure 2(a2i)), while GAC gives access to the carboxyl group, which subsequently reacts with amino groups of lysine to form an amide (Figure 2(a2ii)).

a. Chemically reactive groups
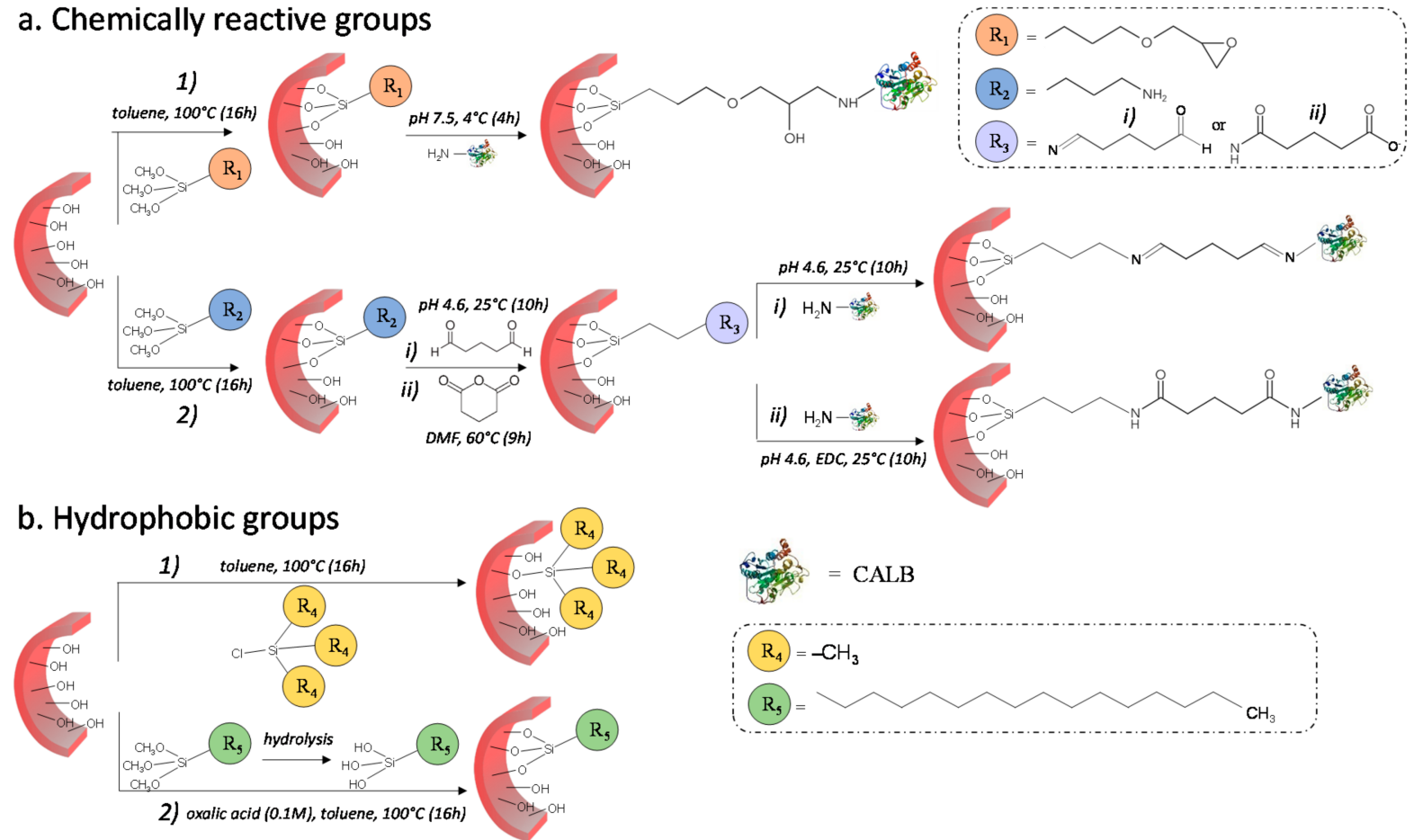

Figure 2. Schematic illustration of the procedure used for the preparation of bifunctional nanoreactors. (a) Enzyme immobilization on the silicified hydrogel functionalized with chemically reactive groups necessary for the covalent binding of the lipase. (a1) The epoxy function alkylates the primary amine of the enzyme yielding a secondary amine. (a2) The amine group in the silica wall reacts with the primary amine of lipase through a bifunctional spacer providing two imine (GAH) or two amide (GAC) bonds. (b) Functionalization of pore wall with trimethylsilyl (b1) and hexadecyl (b2) groups necessary for the interfacial activation of the lipase.

In the process of hydrophobization of silicified hydrogel (Figure 2b), CTMS first reacts with surface silanols yielding trimethylsilyl groups $\left(\mathrm{Si}\left(\mathrm{CH}_{3}\right)_{3}\right)$ (Figure 2(b1)) and releasing hydrochloric acid $(\mathrm{HCl})$. On the other hand, in the case of HDTMS, because of the high degree of hydrophobicity of the hexadecyl group (C16), the silane was first hydrolyzed in an oxalic acid solution $(0.1 \mathrm{M})$, then grafted through condensation with surface silanols (Figure 2(b2)).

To examine the impact of the different functional groups on the catalytic activity of CALB, three series of bifunctional materials were prepared by simultaneous functionalization with (i) CTMS and GPTMS, (ii) HDTMS and APTMS activated with GAH, and (iii) CTMS and APTMS using GAH or GAC as bifunctional spacers. The resulting materials were characterized using TG analysis together with ATR-FTIR spectroscopy.

\subsubsection{Characterization of Biocatalysts}

\section{(a) Sihgel@CTMS@GPTMS@CALB}

The FT-IR spectra of CTMS- and GPTMS-functionalized Sihgel, before and after CALB immobilization, are shown in Figure 3A. The as-synthesized silicified hydrogel (Figure 3(Aa)) displays a strong absorption band at $1036 \mathrm{~cm}^{-1}$ ascribed to the asymmetric stretching vibrations of the $\mathrm{Si}-\mathrm{O}-\mathrm{Si}$ bond [43] that overlaps with the ring vibrational modes of glycosyl units in $\alpha$-CD [44]. Two additional bands appear at $798 \mathrm{~cm}^{-1}$ and $953 \mathrm{~cm}^{-1}$ arising respectively from the symmetric stretching vibrations of $\mathrm{Si}-\mathrm{O}-\mathrm{Si}$ bond and $\mathrm{Si}-\mathrm{OH}$ 
groups [43]. Furthermore, the bands in the $2960-2890 \mathrm{~cm}^{-1}$ region are typical of $\mathrm{C}-\mathrm{H}$ vibration from both $\alpha-\mathrm{CD}$ and Pluronic F127.
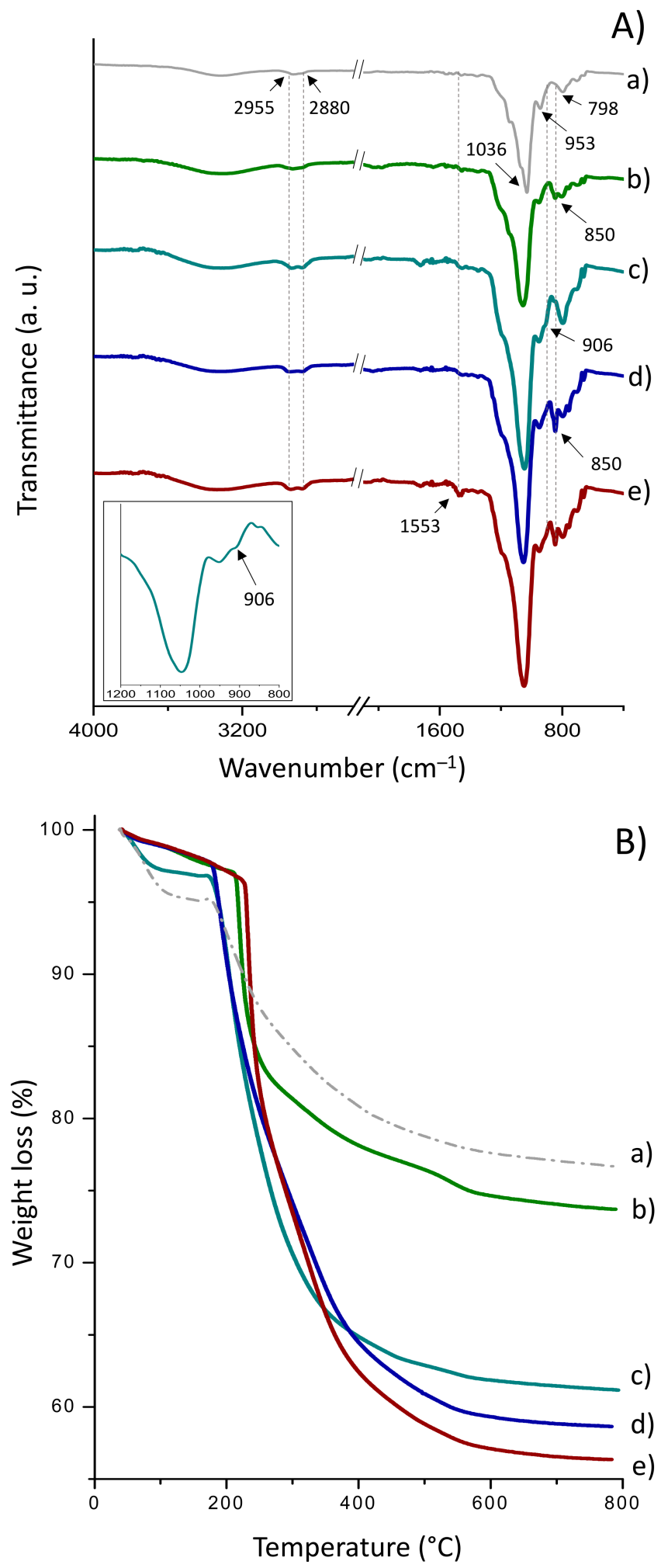

Figure 3. ATR FTIR spectra (A) and TG curves (B) for (a) as-synthesized Sihgel, (b) Sihgel@CTMS, (c) Sihgel@GPTMS, (d) Sihgel@CTMS@GPTMS, and (e) Sihgel@CTMS@GPTMS@CALB. The low intensity of the band at $906 \mathrm{~cm}^{-1}$ suggests that part of epoxy groups may have been opened into diols during reaction with surface silanols. 
Grafting of trimethylsilyl groups on the Sihgel@CTMS material (Figure 3(Ab)) was confirmed by the increase in intensity of the symmetric and asymmetric $\mathrm{C}-\mathrm{H}$ stretching vibrations from aliphatic $-\mathrm{CH}_{3}$ groups at $2880 \mathrm{~cm}^{-1}$ and $2955 \mathrm{~cm}^{-1}$ respectively, as well as the $\mathrm{Si}-\mathrm{C}$ stretching vibration at $850 \mathrm{~cm}^{-1}$ from $-\mathrm{O}-\mathrm{SiCH}_{3}$ end groups $[43,45]$. Upon surface modification with GPTMS (Figure 3(Ac)), a new band appeared at $906 \mathrm{~cm}^{-1}$ originating from the epoxide ring vibration [46]. However, its low intensity suggests that part of epoxides may have been opened into diols during reaction with surface silanols. On the other hand, in the case of Sihgel@CTMS@GPTMS (Figure 3(Ad)), the bands at $850 \mathrm{~cm}^{-1}$ and $906 \mathrm{~cm}^{-1}$ confirm surface functionalization with both hydrophobic and reactive groups. Moreover, upon enzyme immobilization (Figure 3(Ae)), the high intensity vibration at $1553 \mathrm{~cm}^{-1}$ originating from the $\mathrm{N}-\mathrm{H}$ bending of free amines in protein is consistent with successful anchoring of the lipase.

The loading amount of organic moieties was determined by TG analysis in the temperature range between $180{ }^{\circ} \mathrm{C}$ and $800{ }^{\circ} \mathrm{C}$ (Figure 3B). The weight loss below $180{ }^{\circ} \mathrm{C}$ was not taken into consideration as it belongs to loss of solvent physically adsorbed into the pores. From the difference between the weight loss of the silicified hydrogel and the weight loss of bare sol-gel silica, the amount of incorporated hydrogel was found to be $13.8 \%$. In the typical curves of CTMS- (Figure 3(Bb)) and GPTMS-functionalized Sihgel (Figure 3(Bc)), the sharp mass drops above $180{ }^{\circ} \mathrm{C}$ arise from the decomposition of organic trimethyl $(4.5 \%)$ and glycidiloxypropyl (17.4\%) moieties respectively (Table 1). Importantly, simultaneous functionalization with CTMS and GPTMS resulted in a total weight loss of $20.7 \%$, which was close to that recorded on Sihgel@CTMS and Sihgel@GPTMS taken together (21.9\%) (Table 1).

Table 1. Parameters deduced from $\mathrm{N}_{2}$-adsorption and TG analysis for the silica materials before and after modification with different functional groups and lipase immobilization.

\begin{tabular}{|c|c|c|c|c|c|}
\hline Sample & $\begin{array}{l}\text { Total Weight } \\
\text { Loss }^{\text {a }}(\%)\end{array}$ & $\begin{array}{c}\text { Effective Weight } \\
\text { Loss }^{b}(\%)\end{array}$ & $\begin{array}{c}D_{g}{ }^{c} \\
\left(\mathrm{mg} \cdot \mathrm{g}^{-1}\right)\end{array}$ & $\begin{array}{l}D_{g}^{\max , d} \\
\left(\mathrm{mg} \cdot \mathrm{g}^{-1}\right)\end{array}$ & $\begin{array}{c}\mathrm{S}_{\operatorname{cov}} \mathrm{e} \\
\left(\mathrm{chain} \cdot \mathrm{nm}^{-2}\right)\end{array}$ \\
\hline Sihgel@CTMS0.33 & 22.3 & 4.5 & 45 & 57 & 0.24 \\
\hline Sihgel@GPTMS0.68 & 35.2 & 17.4 & 174 & 105 & 0.41 \\
\hline Sihgel@CTMS0.33@GPTMS0.68 & 38.5 & 20.7 & 207 & - & - \\
\hline Sihgel@CTMS0.33@GPTMS0.68@CALB & 41.0 & 2.5 & 25 & - & - \\
\hline Sihgel@HDTMS0.33 & 24.5 & 6.7 & 67 & 85 & 0.07 \\
\hline Sihgel@APTMS0.16 & 27.1 & 9.3 & 93 & 68 & 0.28 \\
\hline Sihgel@HDTMS@APTMS-GAH & 31.1 & 13.3 & 133 & - & - \\
\hline Sihgel@HDTMS@APTMS-GAH@CALB & 32.5 & 1.4 & 14 & - & - \\
\hline Sihgel@CTMS@APTMS-GAC & 39.2 & 21.4 & 214 & - & - \\
\hline Sihgel@CTMS@APTMS-GAC@CALB & 45.7 & 6.5 & 65 & - & - \\
\hline Sihgel@CTMS@APTMS-GAH & 35.9 & 18.1 & 181 & - & - \\
\hline Sihgel@CTMS@APTMS-GAH@CALB & 41.3 & 5.4 & 54 & - & - \\
\hline
\end{tabular}

${ }^{a}$ Weight loss between 180 and $700{ }^{\circ} \mathrm{C},{ }^{b}$ weight loss corrected by the decomposition profile of sol-gel silica before surface functionalization, ${ }^{\mathrm{C}}$ grafting density of functional groups between 180 and $700^{\circ} \mathrm{C},{ }^{\mathrm{d}}$ maximum grafting density determined from Equation (2) (see Experimental part), ${ }^{\mathrm{e}}$ surface coverage determined from Equation (1) (see Experimental part).

The grafting densities (Dg) on Sihgel@CTMS and Sihgel@GPTMS were found equal to be $45 \mathrm{mg} / \mathrm{g}$ and $174 \mathrm{mg} / \mathrm{g}$ respectively. Moreover, using Equation (1) (see Experimental part), the corresponding surface coverages $\left(S_{\text {cov }}\right)$ were determined to be $0.24 \mathrm{chain} / \mathrm{nm}^{2}$ and 0.41 chain $/ \mathrm{nm}^{2}$ respectively. The maximum grafting densities $\left(\mathrm{D}_{\mathrm{g}}{ }^{\mathrm{max}}\right)$ of trimethyl and glycidoxypropyl groups that could theoretically be grafted on the surface of the host matrix were also calculated assuming that GPTMS was fully hydrolyzed and that trimethyl groups from CTMS formed a monolayer on the hydrogel surface. Therefore, considering that trimethyl moieties occupy a surface area of $0.43 \mathrm{~nm}^{2}$ [47] and that the surface occupied by glycidoxypropyl groups is $0.2 \mathrm{~nm}^{2}$ [48], the maximum grafting densities were determined to be $57 \mathrm{mg} / \mathrm{g}$ and $105 \mathrm{mg} / \mathrm{g}$ respectively (Table 1). By comparing the experimental data 
with the theoretical predictions, it appears that CTMS most likely forms a thin monolayer on the hydrogel surface, whereas GPTMS gives rise to a thicker layer, probably due to the higher reactivity and sol-gel reticulation of GPTMS network [49]. Furthermore, the approximate amount of grafted protein, determined by the difference in the mass loss between Sihgel@CAG@CALB (B,e) and Sihgel@CAG $(B, d)$, was determined to be 2.5\% (Table 1).

\section{(b) Sihgel@HDTMS@APTMS@CALB}

Figure 4A displays the FTIR spectra of HDTMS- and APTMS-functionalized material before and after enzyme immobilization. Relative to pristine Sihgel (Figure 4 (Aa)), the spectrum of HDTMS-functionalized Sihgel (Figure $4(\mathrm{Ab})$ ) displays a new vibration band at $1460 \mathrm{~cm}^{-1}$ characteristic of the $-\mathrm{CH}_{2}$ and $-\mathrm{CH}_{3}$ bendings in the hexadecyl chains [43] Moreover, the bands at 2925 and $2854 \mathrm{~cm}^{-1}$ assigned respectively to the asymmetric and the symmetric stretching vibrations of $\mathrm{CH}_{2}$ groups [50] further confirm grafting of the hydrophobic silane. On the other hand, the spectrum of APTMS-functionalized Sihgel (Figure 4 (Ac)) presents two vibrations at $1553 \mathrm{~cm}^{-1}$ and $1454 \mathrm{~cm}^{-1}$ consistent with the $\mathrm{N}-\mathrm{H}$ bending of the primary amine and the symmetric $\mathrm{CH}_{2}$ bending of $\mathrm{Si}-\mathrm{CH}_{2}$ groups respectively. Further, the bifunctional material (Sihgel@HDTMS@APTMS-GAH) displayed the typical vibration bands of both silanes indicating successful surface modification (Figure $4(\mathrm{Ad})$ ). Notably, upon enzyme immobilization, the increase in intensity of the vibration at $1553 \mathrm{~cm}^{-1}$ corresponding to $\mathrm{N}-\mathrm{H}$ bending of free amines in protein, together with the band at $1644 \mathrm{~cm}^{-1}$ assigned to the imine bond $(\mathrm{C}=\mathrm{N})$, confirmed that lipase was successfully anchored on the functionalized support (Figure 4 (Ae)).

From TG analysis (Figure $4(\mathrm{Ba}, \mathrm{b})$ ), the thermal decomposition of hexadecyl groups from HDTMS gave a grafting density of $67 \mathrm{mg} / \mathrm{g}$, higher than that of trimethyl groups from CTMS (45 mg/g) (Table 1$)$. However, the corresponding surface coverage $\left(\mathrm{S}_{\text {cov }}\right)$ obtained with HDTMS was extremely low $\left(0.07\right.$ chain $\left./ \mathrm{nm}^{2}\right)$, indicating incomplete silylation of surface silanols (Table 1). Note that Sihgel@APTMS yielded a grafting density of $93 \mathrm{mg} / \mathrm{g}$ and a surface coverage of $0.28 \mathrm{chain} / \mathrm{nm}^{2}$, which are both lower than the values recorded on Sihgel@GPTMS (174 mg/g and 0.41 chain $/ \mathrm{nm}^{2}$ respectively). Furthermore, the weight loss resulting from the thermal decomposition of the protein was found equal to $3.6 \%$. Comparison of experimental and theoretical data $\left(67 \mathrm{mg} \cdot \mathrm{g}^{-1} \mathrm{vs} .85 \mathrm{mg} \cdot \mathrm{g}^{-1}\right)$ reveals that the hexadecyl groups provide only partial coverage of the hydrogel surface probably due to incomplete hydrolysis of the silane and insufficient interaction with silanols available on the support surface.

(c) Sihgel@CTMS@APTMS@CALB: Effect of the linker (glutaric anhydride vs. glutaraldehyde)

Activation of the primary amino groups with GAC resulted in the appearance of a new band at $1723 \mathrm{~cm}^{-1}$ assigned to the $\mathrm{C}=\mathrm{O}$ stretch modes of aldehyde groups (Figure 5(Aa)). Moreover, reaction of both GAH and GAC with surface amino groups was confirmed by the $\mathrm{CH}_{2}$ bends at $1408 \mathrm{~cm}^{-1}$, as well as the $\mathrm{C}=\mathrm{N}$ stretching modes at $1644 \mathrm{~cm}^{-1}$ (Figure $5(\mathrm{Aa}, \mathrm{c})$ ). Other bands at $2948 \mathrm{~cm}^{-1}$ and $2857 \mathrm{~cm}^{-1}$ on Sihgel@CTMS@APTMS@GAC can be ascribed to aldehyde $\mathrm{C}-\mathrm{H}$ and alkyl $\mathrm{C}-\mathrm{H}$ stretching vibrations, respectively. In all functionalized solids, the band at $850 \mathrm{~cm}^{-1}$ corroborates with the $\mathrm{Si}-\mathrm{C}$ stretching vibration of $-\mathrm{O}-\mathrm{SiCH}_{3}$ end groups from CTMS. Moreover, lipase immobilization on both supports was confirmed by the vibration at $1554 \mathrm{~cm}^{-1}$ assigned to the $\mathrm{N}-\mathrm{H}$ bending of free amines (Figure $5(\mathrm{Ab}, \mathrm{d})$ ).

From the thermogravimetric curves (Figure 5B), the effective weight loss on Sihgel@ CTMS@APTMS-GAC was determined to be $21.4 \%$, which was almost $3.2 \%$, higher than that recorded on Sihgel@CTMS@APTMS-GAH (18.1\%). Such a difference is probably due to the higher crosslinking ability of GAC with respect to GAH, which may also explain its higher enzyme-loadings capacity (6.5\% vs. 5.4\%) (Figure 5(Bb,d) and Table 1). 


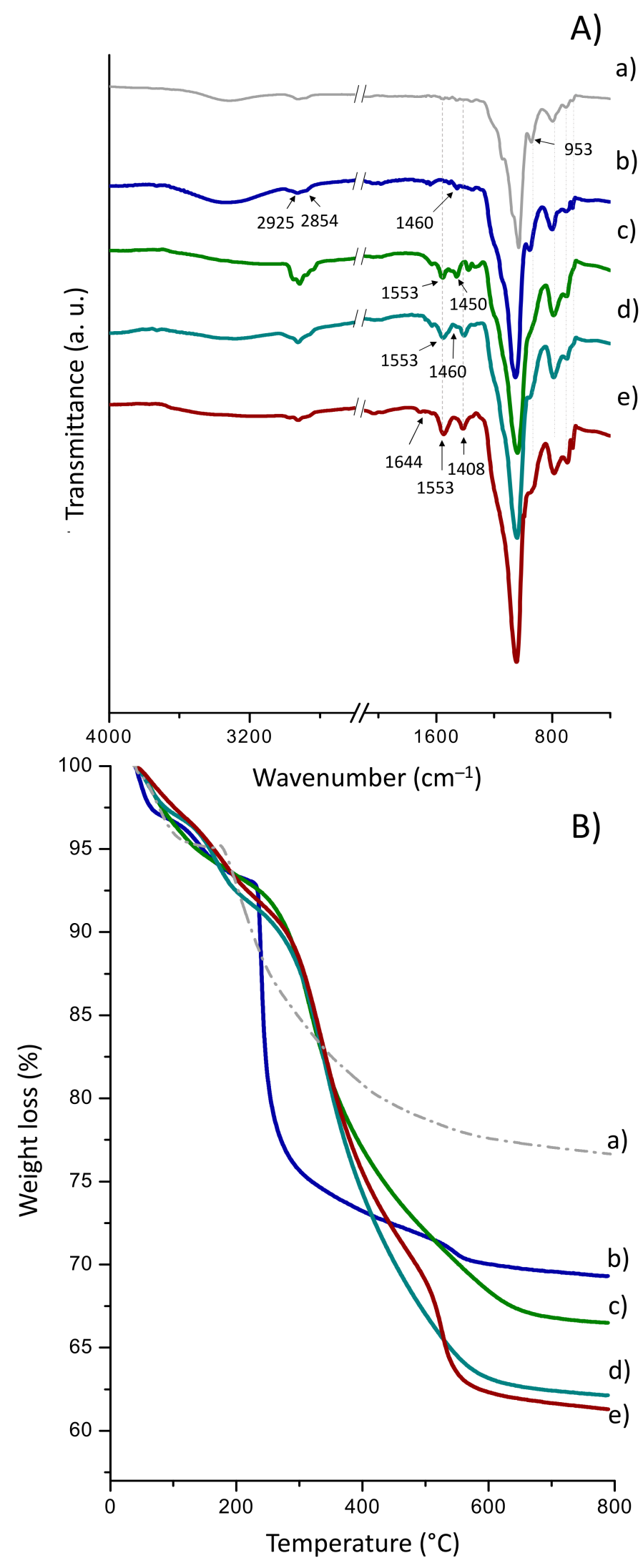

Figure 4. ATR FTIR spectra (A) and TG curves (B) for (a) as-synthesized Sihgel, (b) Sihgel@HDTMS, (c) Sihgel@APTMS, (d) Sihgel@HDTMS@APTMS-GAH, and (e) Sihgel@HDTMS@APTMSGAH@CALB. 

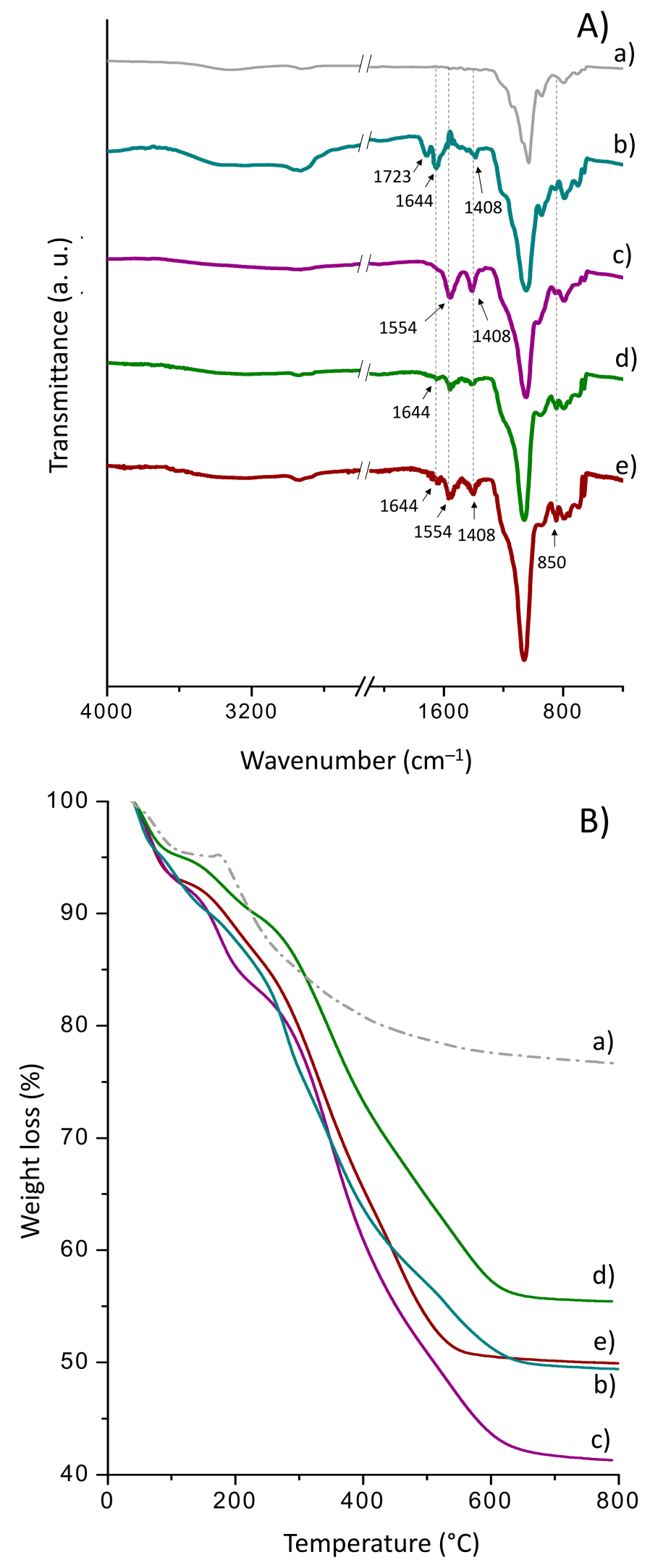

Figure 5. ATR-FTIR spectra (A) and TG curves (B) for (a) as-synthesized Sihgel, (b) Sihgel@ CTMS@APTMS-GAC, (c) Sihgel@CTMS@APTMS-GAC@CALB, (d) Sihgel@CTMS@APTMS-GAH, and (e) Sihgel@CTMS@APTMS-GAH@CALB. 


\section{Catalytic Activity}

The oxidation of DFF to FDCA proceeds via a chemoenzymatic cascade reaction involving two consecutive steps. First, the lipase CALB catalyzes the perhydrolysis of ethyl acetate with hydrogen peroxide yielding peracetic acid. Then, the peracid oxidizes in situ the aldehyde group of DFF to carboxylic acid yielding the 5-formylfuran-2-carboxylic acid (FFCA), which is ultimately converted to FDCA (Table 2). In all our experiments, reaction was assessed by adding 2.0 equivalents $\mathrm{H}_{2} \mathrm{O}_{2}(30 \% v / v)$ in a mixture of ethyl acetate (EtOAc) and tert-butanol (tBuOH) $(1: 1 v / v)$ containing $10 \mathrm{mM}$ DFF. Reaction products were analyzed using ${ }^{1} \mathrm{H}$ NMR and HPLC. $\mathrm{tBuOH}$ was used as a solvent to avoid deactivation of CALB because of the high acidity of the acyl donor (EtOAc). Indeed, in the oxidation of furfural, Krystof et al. [51] have shown that reactions conducted in neat EtOAc, acting both as acyl donor and solvent, can lead to lower yields in furoic acid with respect to reaction performed in a $\mathrm{tBuOH} / \mathrm{EtOAc}$ mixture.

Under those conditions, free CALB was not active (entry 1). However, when $2 \mathrm{mg}$ lipase was immobilized by ionic bonding on Sihgel@CTMS (acetate buffer pH 4.6), 88\% DFF conversion and 19\% FDCA yield could be achieved (entry 2). Notably, DFF conversion was complete when the lipase loading was increased to $4 \mathrm{mg}$, giving $72 \%$ yield in FDCA (entry 3). When CALB was covalently attached to Sihgel@CTMS@GPTMS prepared with different GPTMS $/ \mathrm{SiO}_{2}$ and CTMS $/ \mathrm{SiO}_{2}$ molar ratios (entries 4 to 10 ), the immobilization rates were in the range of 89 to $97 \%$, confirming the effectiveness of the epoxy ring as a reactive group for covalent anchoring of the protein. Notably, the DFF conversions achieved with $2 \mathrm{mg}$ CALB were complete with all catalysts, while the FDCA yields were found to be dependent on GPTMS loading, decreasing from 42 to $34 \%$ when the GPTMS $/ \mathrm{SiO}_{2}$ molar ratio was increased from 0.68 to 1.50 (entries 4-6). In particular, with $4 \mathrm{mg}$ CALB, the FDCA yields could reach $70 \%$ and $51 \%$ using GPTMS $/ \mathrm{SiO}_{2}$ molar ratios of 0.68 (entry 7) and 0.34 (entry 8) respectively. Similarly, increasing the $\mathrm{CTMS} / \mathrm{SiO}_{2}$ ratio from 0.33 to 0.66 resulted in a drop of the FDCA yield from 70\% (entry 7) to $41 \%$ (entry 9). However, a FDCA yield of $72 \%$ could be achieved by increasing the lipase loading to $8 \mathrm{mg}$, (entry 10). Taking into account the best performance/cost ratio, Sihgel@CTMS0.33@GPTMS0.68@CALB2 was found to be the most efficient bioreactor, giving a specific activity of $20.8 \mu \mathrm{mol} \mathrm{g}^{-1} \mathrm{~min}^{-1}$, a TTN of $288.8 \mathrm{~mol}^{-1}$ and a TOF of $41.3 \mathrm{~min}^{-1}$ (entry 4). Taken together, these results demonstrated that simultaneous functionalization of the silicified hydrogel with GPTMS and CTMS is an effective way for covalent anchoring and interfacial activation of the lipase.

The effect of hydrophobic groups on enzyme activity was established by comparing trimethyl- and hexadecyl- functionalized materials at the same silane $/ \mathrm{SiO}_{2}$ molar ratio of 0.33 . Regardless the immobilization approach (physisorption or covalent bond), the enzyme loadings on Sihgel@HDTMS ranged from $96 \%$ to $99 \%$ (entries 11 to 13, 15). Notably, the FDCA yield increased from $17 \%$ (entry 11 ) to $50 \%$ (entry 12) when CALB loading was increased from $2 \mathrm{mg}$ to $4 \mathrm{mg}$. It is worth noting that although HDTMS acts as an effective hydrophobic agent, with $4 \mathrm{mg}$ CALB, its effect on the interfacial activation of lipase seems to be less pronounced than that of CTMS (50\% vs. $72 \%$ FDCA yields) (entries 12 , 3). Accordingly, the bifunctional Sihgel@HDTMS@CTMS@CALB4 biocatalyst containing equimolar amounts of CTMS and HDTMS achieved $60 \%$ yield in FDCA (entry 13), which represents an intermediate value between CTMS (72\%, entry 3$)$ and HDTMS (50\%, entry 12) taken separately. 
Table 2. Catalytic performance of lipase CALB immobilized in Sihgel modified with different functional groups in the oxidation of DFF to FDCA a

\begin{tabular}{|c|c|c|c|c|c|c|c|c|c|}
\hline \multirow[b]{2}{*}{ Entry } & \multirow[b]{2}{*}{ Catalyst } & \multirow[b]{2}{*}{$\begin{array}{l}\text { Immobilization } \\
\text { Efficiency }(\%)^{b}\end{array}$} & \multirow{2}{*}{$\begin{array}{l}\text { Loading } \\
\text { Capacity } \\
\text { (wt.\%) }^{c}\end{array}$} & \multirow{2}{*}{$\begin{array}{c}\text { DFF } \\
\text { Conversion } \\
(\%)\end{array}$} & \multicolumn{2}{|c|}{ Yield (\%) } & \multirow[b]{2}{*}{$\begin{array}{c}\text { Specific Activity } \\
\left(\mu \mathrm{mol} \mathrm{g}^{-1} \mathrm{~min}^{-1}\right) \mathrm{g}\end{array}$} & \multirow[b]{2}{*}{$\begin{array}{c}\text { TTN } \\
\left(\mathrm{mol} \mathrm{mol}^{-1}\right)^{h}\end{array}$} & \multirow[b]{2}{*}{$\begin{array}{c}\text { TOF } \\
\left(\min ^{-1}\right)^{i}\end{array}$} \\
\hline & & & & & $\begin{array}{c}\text { FFCA } \\
(\%)\end{array}$ & $\begin{array}{c}\text { FDCA } \\
(\%)\end{array}$ & & & \\
\hline 1 & free CALB & - & - & 0 & 0 & 0 & 0 & 0 & 0 \\
\hline 2 & Sihgel@CTMS0.33 d @CALB2 e & 95 & 9.5 & 88 & 69 & 19 & 8.5 & 117.4 & 16.8 \\
\hline 3 & Sihgel@CTMS0.33@CALB4 & 95 & 19 & 100 & 28 & 72 & 18.0 & 250.1 & 35.7 \\
\hline 4 & Sihgel@CTMS0.33@GPTMS0.68@CALB2 & 96 & 9.6 & 100 & 58 & 42 & 20.8 & 288.8 & 41.3 \\
\hline 5 & Sihgel@CTMS0.33@GPTMS1.00@CALB2 & 97 & 9.7 & 100 & 61 & 39 & 19.1 & 265.4 & 37.9 \\
\hline 6 & Sihgel@CTMS0.33@GPTMS1.50@CALB2 & 97 & 9.7 & 100 & 66 & 34 & 16.7 & 231.3 & 33.0 \\
\hline 7 & Sihgel@CTMS0.33@GPTMS0.68@CALB4 & 89 & 17.8 & 100 & 30 & 70 & 18.7 & 259.6 & 37.1 \\
\hline 8 & Sihgel@CTMS0.33@GPTMS0.34@CALB4 & 96 & 19.2 & 100 & 49 & 51 & 12.6 & 175.3 & 25.0 \\
\hline 9 & Sihgel@CTMS0.66@GPTMS0.68@CALB4 & 92 & 18.4 & 100 & 59 & 41 & 10.6 & 147.1 & 21.0 \\
\hline 10 & Sihgel@CTMS0.66@GPTMS0.68@CALB8 & 96 & 38.4 & 100 & 28 & 72 & 8.9 & 123.8 & 17.7 \\
\hline 11 & Sihgel@HDTMS0.33@CALB2 & 96 & 9.6 & 82 & 65 & 17 & 6.9 & 95.8 & 13.7 \\
\hline 12 & Sihgel@HDTMS0.33@CALB4 & 99 & 19.8 & 100 & 50 & 50 & 12.0 & 166.7 & 23.8 \\
\hline 13 & Sihgel@HDTMS0.33@CTMS0.33@CALB4 & 98 & 19.6 & 100 & 40 & 60 & 14.6 & 202 & 28.9 \\
\hline 14 & Sihgel@APTMS0.16-GAH@CALB4 & 89 & 8.9 & 44 & 44 & 0 & 0.0 & 0.0 & 0.0 \\
\hline
\end{tabular}


Table 2. Cont.

\begin{tabular}{|c|c|c|c|c|c|c|c|c|c|}
\hline 15 & Sihgel@HDTMS0.33@APTMS0.16-GAH@CALB2 & 96 & 9.6 & 85 & 72 & 13 & 5.5 & 76.0 & 10.9 \\
\hline 16 & Sihge1@CTMS0.33@APTMS0.16-GAC@CALB2 & 95 & 9.5 & 100 & 59 & 41 & 20.6 & 284.8 & 40.7 \\
\hline 17 & Sihgel@CTMS0.33@APTMS0.16-GAH@CALB2 & 96 & 9.6 & 100 & 33 & 67 & 33.2 & 460.6 & 65.8 \\
\hline 18 & Sisg f @CTMS0.33@APTMS0.16-GAH@CALB2 & 72 & 7.2 & 24 & 24 & 0 & 0.0 & 0.0 & 0.0 \\
\hline
\end{tabular}

${ }^{a}$ Reaction conditions: $10 \mathrm{mM} \mathrm{DFF}, 2 \mathrm{~mL}$ EtOAc/tBuOH (1:1. $\left.v / v\right)$, sequential addition of 2.0 equivalents aqueous $\mathrm{H}_{2} \mathrm{O}_{2}(30 \% v / v)$ every hour for seven hours, temperature $40{ }^{\circ} \mathrm{C}$ reaction time $7 \mathrm{~h} .{ }^{\mathrm{b}}$ Calculated from Equation (3) (see Experimental part). ${ }^{\mathrm{c}}$ Calculated from Equation (4) (see Experimental part). ${ }^{\mathrm{d}} \mathrm{CTMS}_{\mathrm{SiO}} \mathrm{molar}$ ratio $=0.33$. ${ }^{\mathrm{e}} 2 \mathrm{mg} \mathrm{CALB}$ in $20 \mathrm{mg}$ support $\left(1.33 \mathrm{mg} / \mathrm{mL}\right.$ CALB in the immobilization solution). ${ }^{\mathrm{f}}$ template-free sol-gel silica. ${ }^{\mathrm{g}}$ specific activity was calculated as $\mu$ mol of product formed (two $\mu$ mol peracid per $\mu$ mol of FDCA) per $\mathrm{g}$ of protein in one minute. ${ }^{\mathrm{h}} \mathrm{TTN}=$ moles of FDCA formed divided by moles of protein. ${ }^{\mathrm{i}} \mathrm{TOF}=\mathrm{TTN}$ divided by reaction time. 
The grafting density cannot explain such difference because it is slightly lower in the CTMS-functionalized material compared to the HDTMS-functionalized one ( $45 \mathrm{mg} / \mathrm{g}$ vs. $67 \mathrm{mg} / \mathrm{g}$, Table 1). Conversely, the surface coverage with hexadecyl chains was found to be almost four times lower than that obtained with trimethyl groups $\left(0.07\right.$ chains $/ \mathrm{nm}^{2}$ vs. 0.28 chains $/ \mathrm{nm}^{2}$ ). Therefore, the partial coverage of the hydrogel surface with hexadecyl moieties appears to be inadequate for the interfacial activation of lipase. Notably, grafting of CALB on the non-hydrophobisized support gave negligible DFF conversion $(44 \%)$ and could not lead to the final product (0\% FDCA yield) (entry 14), while $85 \%$ DFF conversion and 13\% FDCA yield could be achieved with the Sihgel@HDTMS0.33@APTMSGAH@CALB2 biocatalyst (entry 15). Taken together, these data indicate that the hydrophobic moieties of the silane and their surface coverage play a key role in optimal activation of the lipase.

On the other hand, comparison of Singel@CTMS@APTMS-GAC@CALB2 (entry 16) and Sihgel@CTMS@APTMS-GAH@CALB2 (entry 17) revealed that glutaric anhydride was a less efficient linker than glutaraldehyde (67\% vs. $41 \%$ FDCA yields), although higher grafting densities were obtained with the former $(223 \mathrm{mg} / \mathrm{g}$ vs. $184 \mathrm{mg} / \mathrm{g})$. This suggests that the CAG-activated chains resulting from succinylation of both amino groups and hydroxy amino acids from protein [52] may probably alter the proper functioning of lipase by masking the hydrophobic trimethyl groups, which are essential for interfacial activation of CALB. It is worth noting that the FDCA yield achieved with the Sihgel@CTMS@APTMS-GAH@CALB2 catalyst (entry 17) was also higher than that obtained with Sihgel@CTMS@GPTMS@CALB2 (entry 4) giving a specific activity of $33.2 \mu \mathrm{mol} \mathrm{g}^{-1} \mathrm{~min}^{-1}$, a TTN of $460.6 \mathrm{~mol}^{-1}$, and a TOF of $65.8 \mathrm{~min}^{-1}$.

These observations highlight the important role played by both grafting and hydrophobic groups on the catalytic performance of immobilized CALB. Indeed, the steric hindrance exerted by the thick layer resulting from crosslinking reactions of the epoxy ring $[40,41]$ may cause conformation constraints on immobilized enzyme, restricting access of substrate to the active site. Conversely, partial covering of hydrogel surface with hardly hydrolysable hexadecyltrimethoxysilane seems not being adequate for the interfacial activation of lipase. Therefore, a proper balance needs to be found between chemically reactive groups and hydrophobic functions for an optimal functioning of the biocatalyst.

\section{Recyclability}

The ability to recycle and reuse the catalyst is one of the most important criteria for industrial applications. Unfortunately, our most efficient catalyst, i.e., Sihgel@CTMS@APTMSGAH@CALB2, could not be reused under the employed reaction conditions since the lipase completely lost its catalytic activity in the second run. Given that the furanic compounds formed during this reaction (FFCA and FDCA) bear carboxylic acid moieties in their cycle, they are likely to lower the $\mathrm{pH}$ in the vicinity of the enzyme, thereby creating an acidic microenvironment that can inhibit the lipase activity [53]. In fact, the $\mathrm{pH}$ of reaction medium was found to decrease at the end of the catalytic test from 4.8 to 3.1. To circumvent limitations due to $\mathrm{pH}$ gradients and assess the recycling potential of the immobilized $\mathrm{CALB}$, we considered covering our biocatalyst with the cationic cross-linked $\beta$-cyclodextrin $(C C L \beta-C D)$ employed as a lipase-stabilizing agent. The polymeric $C D$ network is obtained by crosslinking native $\beta-C D$ with epichlorohydrin (EP) in the presence of a cationizing agent, the glycidyltrimethylammonium chloride (GTMAC) [54]. CCL $\beta$-CD has received great interest as high performant carrier in drug [55,56] and gene delivery systems [57], as well as in heterogeneous catalysis [58]. Because this CD-based polymer contains quaternary ammoniums on its structure (Figure 6A), it should be able to protect the enzyme against $\mathrm{pH}$ variations, thus acting as a "solid buffer". 

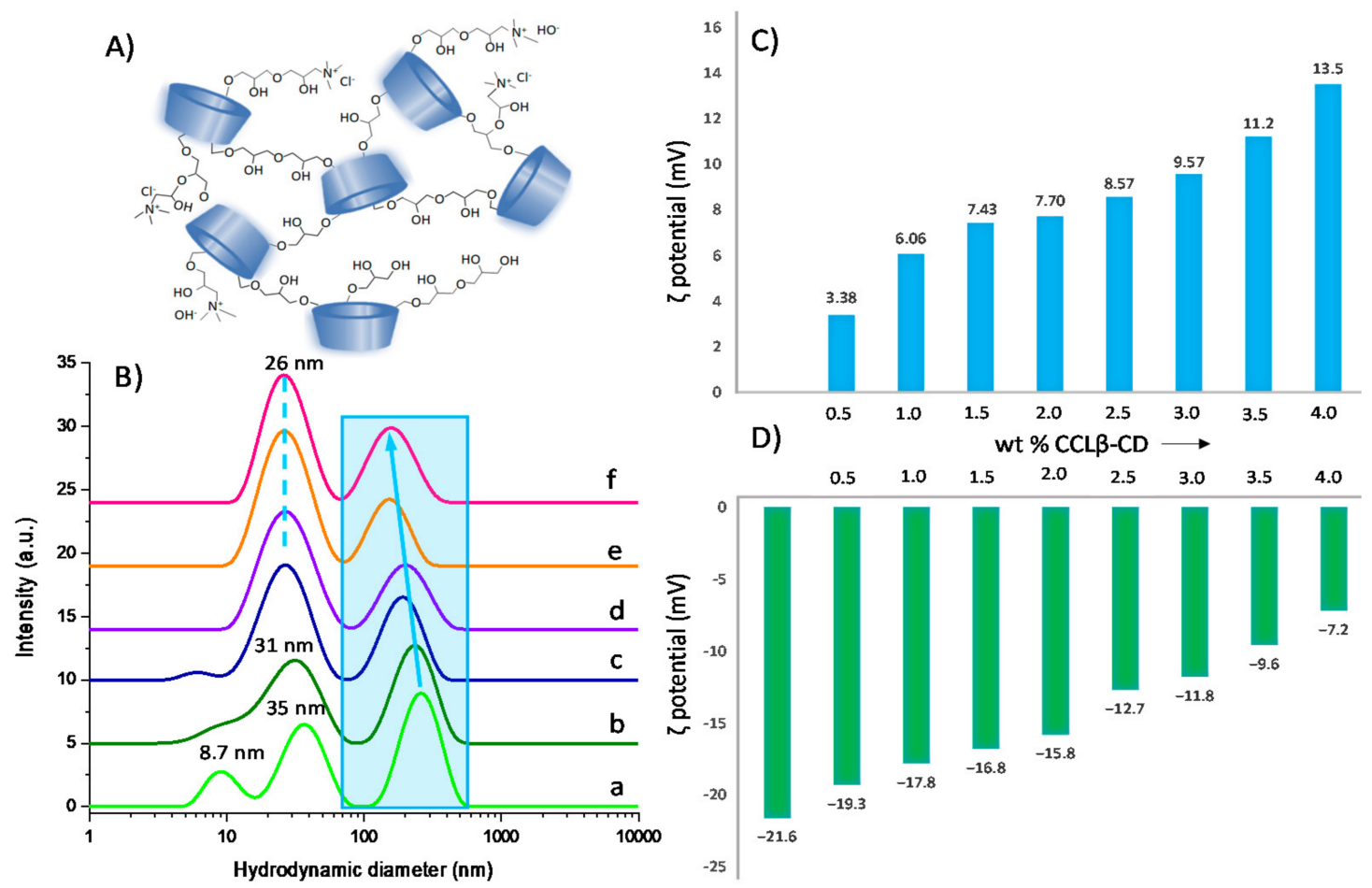

Figure 6. Schematic structure of cross-linked $\beta$-cyclodextrin oligomers (A); DLS data of mixtures prepared with $2 \mathrm{mg} / \mathrm{mL}$ CALB and different wt. \% of CCL $\beta-C D$ (a: $0 \%$; b: $0.5 \%$; c: $1.5 \%$; d: $2.5 \%$; e: $3.0 \%$; $\mathrm{f:} 4.0 \%$ ) (B). Zeta potential of aqueous solutions prepared increasing wt. \% of CCL $\beta-C D$ without (C) and with $2 \mathrm{mg} / \mathrm{mL}$ CALB (D).

Under the immobilization conditions employed, at $\mathrm{pH}$ below the isoelectric point of CALB (acetate buffer, $\mathrm{pH} 4.6$ ), the presence of positive charges on CCL $\beta$-CD can result in favorable electrostatic interactions with the negatively charged enzyme. Evidence for such interactions was provided by DLS measurements. Thus, at $25{ }^{\circ} \mathrm{C}$, CALB solution $(2 \mathrm{mg} / \mathrm{mL})$ displayed three size populations that could be attributed to free enzyme $(8.7 \mathrm{~nm})$ and its aggregates $(35 \mathrm{~nm}$ and $260 \mathrm{~nm})$ (Figure 6B). Upon addition of CCL $\beta-C D$ up to $4 \mathrm{wt} \%$, the size of the CALB aggregates decreased from 260 to $160 \mathrm{~nm}$ as a result of their dissociation after interaction with the cationic polymer. Notably, the size population at $8.7 \mathrm{~nm}$ corresponding to free enzyme totally disappeared at the expense of CALB/CCL $\beta$ $\mathrm{CD}$ assemblies with an average diameter of $25-30 \mathrm{~nm}$. Zeta potential measurements also confirmed interaction between the two entities. For instance, in the enzyme-free CCL $\beta-C D$ solution (Figure $6 \mathrm{C}$ ), $\zeta$ potential increased from +3.38 to $+13.5 \mathrm{mV}$ with polymer amount, while negative values were obtained in the CALB/CCL $\beta-C D$ mixture, increasing from -21.6 to $-7.2 \mathrm{mV}$ with CCL $\beta$-CD loading. Overall, our results confirm that electrostatic interactions take place between CALB and CCL $\beta-C D$ in aqueous solution, yielding stable supramolecular assemblies.

With a surface coverage of $2 \mathrm{wt} \%$ in CCL $\beta-C D$, the recyclability of the most efficient nanoreactor, i.e., Sihgel@CTMS@APTMS-GAH@CALB was then evaluated and the activities obtained across three consecutive runs are shown in Figure 7. Although a drop in the FDCA yield was noticed from $100 \%$ to $38 \%$ in the second run and to $25 \%$ in the third one, the DFF conversions were still high $(77 \%)$, with FFCA being the only intermediate (52\%). We explain such a decrease in the FDCA yield by the large number of small particles that were lost at the very first rinsing step, causing a decrease of the amount of lipase remaining in the reaction mixture. In fact, the silicified hydrogel is very polydisperse in size. It is composed of very small particles originating from free (uncomplexed) cyclodextrin and larger ones formed by silicification of polypseudorotaxanes and polypseudorotaxane-based nanocrystallites. All of these species are present in the starting F127/ $\alpha-\mathrm{CD}$ hydrogel and 
are replicated after silicification producing a wide range of particle sizes, which are at the origin of the microstructure heterogeneity. At the end of the first run, we observed an important decrease in the amount of residual solid, which was actually almost half lower $(10.5 \mathrm{mg})$ than that introduced in the reaction medium $(20.8 \mathrm{mg})$, then a stabilization to $8.4 \mathrm{mg}$ in the second run and to $7.9 \mathrm{mg}$ in the third one. This suggests that almost all tiny particles were removed during the first rinsing step. However, we also noticed that the rinsing solution was able to catalyze effectively the DFF oxidation, achieving conversions close to $100 \%$ (Figure S2, ESI). Given that free CALB was not active in this reaction (entry 1 , Table 2), this in an indication that enzyme leaching that may result from the hydrolysis of the imine bond should not be significant under these modified conditions. Overall, these results confirm that CCL $\beta-C D$ is a good stabilizing agent for our biocatalyst since it effectively protects the enzyme against deactivation under acidic conditions. Nevertheless, CCL $\beta-C D / C A L B$ molar ratio in the nanoreactor is an important parameter that needs to be further investigated in the future in order to optimize the effectiveness of recycling process.

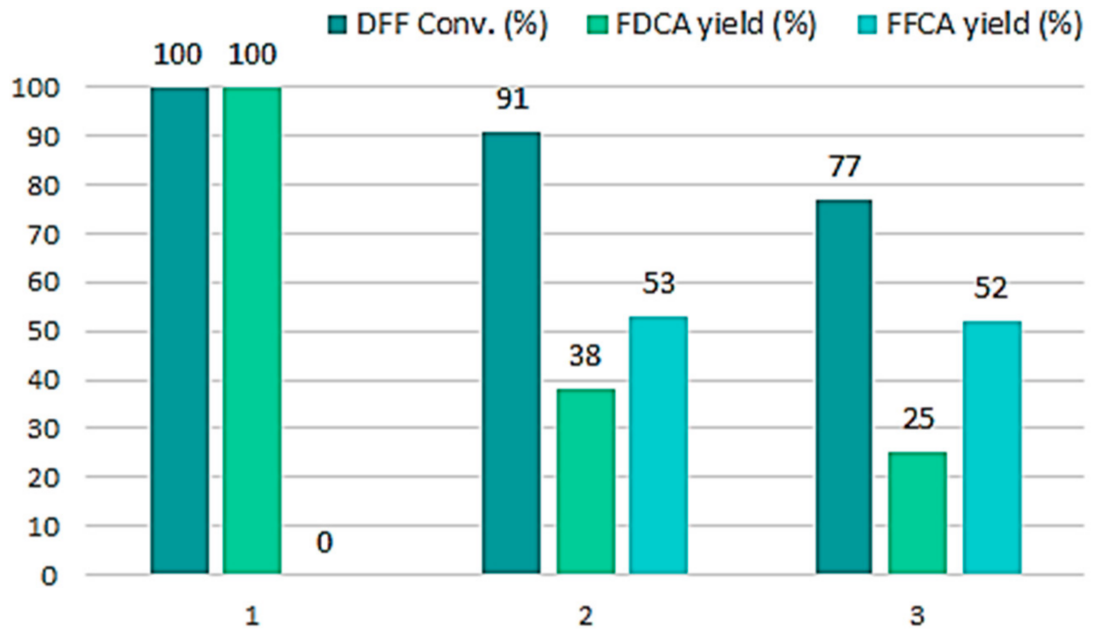

Figure 7. Catalytic recyclability of $\mathrm{SiO}_{2} @ C T M S @ A P T M S-G A H @ C A L B @ C C L \beta-C D$ biocatalyst. Reaction conditions: $10 \mathrm{mM} \mathrm{DFF}, 2 \mathrm{~mL}$ EtOAc/tBuOH $(1: 1 \mathrm{v} / \mathrm{v})$, sequential addition of 2.0 eq. $\mathrm{H}_{2} \mathrm{O}_{2}(30 \%$ $v / v$ ) every hour for seven hours, temperature $40^{\circ} \mathrm{C}$, reaction time $24 \mathrm{~h}$.

\section{Conclusions}

In summary, we have shown that the hierarchically porous silica monoliths obtained by silicification of a supramolecular Pluronic F127 / $\alpha$-cyclodextrin hydrogel act as a promising host matrices for the immobilization of lipase B from Candida antarctica. Functionalization of the silicified hydrogel surface with chemically reactive groups (epoxide and primary amine) and hydrophobic functions (trimethyl and hexapropyl) permitted covalent anchoring and interfacial activation of the lipase. Comparison of the catalytic activities of different catalysts in the oxidation of 2,5-diformylfuran demonstrated the necessity to find a balance between the density of surface coverage and hydrophobic chain length. Therefore, the dense organic layer obtained with (3-glycidiloxypropyl) trimethoxysilane resulting from crosslinking reactions of the epoxy ring was found to be detrimental for lipase activity. Similarly, using glutaric anhydride (GAC) as a spacer on the (3-aminopropyl) trimethoxysilane-functionalized material caused a decline in enzyme activity with respect to glutaraldehyde. On the other hand, the hydrophobic chlorotrimethylsilane with a shorter chain length was found to provide better coverage of the hydrogel surface compared to hexadecyltrimethoxysilane and was more efficient for the interfacial activation of CALB. Among the different biocatalysts, Sihgel@CTMS@APTMS-GAH@CALB gave the best catalytic performance in the oxidation of DFF, achieving full DFF conversion with $67 \%$ FDCA yield after $7 \mathrm{~h}$ at $40{ }^{\circ} \mathrm{C}$ and almost quantitative FDCA yield after $24 \mathrm{~h}$. While immobilized CALB was completely deactivated after the first run, the use of cationic 
cross-linked $\beta$-cyclodextrin as a stabilizing agent permitted to significantly increase the operational stability of lipase, enabling efficient recycling and reuse of the biocatalyst in at least three cycles. This study opens up new perspectives on the use of hierarchically porous supramolecular hydrogels in construction of other chemoenzymatic cascades integrating enzymatic and heterogeneous catalysts for spatially confined chemo-enzymatic reactions.

\section{Experimental}

\subsection{Materials}

Lipase B from Candida antarctica (CALB), recombinant from Aspergillus oryzae (Mw $33 \mathrm{kDa}$ ) was purchased from Sigma Aldrich (Saint-Quentin-Fallavier, France). CALB contains 317 amino acid residues [59] and its active site is composed of a catalytic triad consisting of nucleophilic serine, histidine, and aspartate or glutamate [60]. Pluronic F127 $\left[\mathrm{PEO}_{100} \mathrm{PPO}_{70} \mathrm{PEO}_{100}\right.$ where $\mathrm{PEO}$ stands for poly(ethylene oxide) and PPO for poly(propylene oxide), average Mw 12,500 g/mol], tetramethyl orthosilicate (TMOS 98\%, Mw $152.22 \mathrm{~g} / \mathrm{mol}$ ), chlorotrimethylsilane (CTMS > 98\%, Mw $108.64 \mathrm{~g} / \mathrm{mol}$ ), hexadecyltrimethoxysilane (HDTMS $>85 \%$, Mw 346.6 g/mol), (3-aminopropyl)-trimethoxysilane (APTMS 97\%, Mw $221.37 \mathrm{~g} / \mathrm{mol}$ ), (3-Glycidyloxypropyl)trimethoxysilane (GPTMS, $\geq 98 \%$, Mw $236.34 \mathrm{~g} / \mathrm{mol}$ ), glutaraldehyde (GAH, 50\% in $\mathrm{H}_{2} \mathrm{O}, \mathrm{Mw} 100.11 \mathrm{~g} / \mathrm{mol}$ ), glutaric anhydride (GAC, 95\%, Mw $114.1 \mathrm{~g} / \mathrm{mol}$ ), N(3-Dimethylaminopropyl)- $\mathrm{N}^{\prime}$-ethylcarbodiimide hydrochloride (EDC hydrochloride $>98 \%$, Mw $191.7 \mathrm{~g} / \mathrm{mol}$ ), 2,5-diformylfuran (DFF 97\%, Mw $124.1 \mathrm{~g} / \mathrm{mol}$ ), 2,5-furandicarboxylic acid (FDCA 97\%, Mw $156.1 \mathrm{~g} / \mathrm{mol}$ ), 5-formylfuran-2-carboxylic acid (FFCA, Mw $140.1 \mathrm{~g} / \mathrm{mol}$ ), phosphate buffer solution ( $50 \mathrm{mM}, \mathrm{pH} 7.5)$, ethylacetate (EtOAc), and tert-butanol (t-BuOH) were purchased from Sigma Aldrich (Saint-Quentin-Fallavier, France). Acetate buffer solution ( $\mathrm{pH}$ 4.6) was procured from Honeywell Fluka (Illkirch, France). Native $\alpha$-cyclodextrin ( $\alpha-\mathrm{CD}, 99 \%$, Mw $972.85 \mathrm{~g} / \mathrm{mol}$ ) was procured from Wacker Chemie GmbH (Lyon, France) while cationic cross-linked $\beta-C D(C C L \beta-C D, M w \sim 20 \mathrm{~kg} / \mathrm{mol})$ was a gift from Roquette Frères (Lestrem, France). The ${ }^{1} \mathrm{H}$ NMR and ${ }^{13} \mathrm{C}$ NMR spectra of polymer in $\mathrm{D}_{2} \mathrm{O}$ are shown in Figure S3, ESI. All chemicals were used as received, without further purification.

\subsection{Preparation of Silicified Hydrogel}

The silicified hydrogel (denoted Sihgel) was prepared according to a previously reported method with some modifications [30]. Briefly, $2.0 \mathrm{~g}$ of $\alpha-\mathrm{CD}(100 \mathrm{mg} / \mathrm{mL})$ was introduced into $20 \mathrm{~mL}$ of a micellar F127 solution $(25 \mathrm{mg} / \mathrm{mL}$ of Pluronic F127 in water). The mixture was stirred at room temperature for $15 \mathrm{~min}$, then stored in a closed vial at $4{ }^{\circ} \mathrm{C}$ for $24 \mathrm{~h}$ until a water-swollen gel formed. The $\mathrm{pH}$ of the hydrogel was measured to be 6.3 . Subsequently, $1.42 \mathrm{~g}$ of TMOS $(\alpha-\mathrm{CD} / \mathrm{TMOS}$ molar ratio $=0.22)$ was added dropwise to the hydrogel and maintained under stirring $(800 \mathrm{rpm})$ at room temperature for $2 \mathrm{~h}$. The mixture was then loaded into a $40-\mathrm{mL}$ Teflon-lined autoclave and heated at $60^{\circ} \mathrm{C}$ for $48 \mathrm{~h}$ to complete the condensation reaction between silanols. The excess of hydrogel was removed by washing several times with water and ethanol.

\subsection{Functionalization of Silicified Hydrogel}

Prior to functionalization with different reactive and hydrophobic groups, $250 \mathrm{mg}$ of the silicified hydrogel (Sihgel) was dried under vacuum conditions at $180{ }^{\circ} \mathrm{C}$ overnight in order to remove any traces of solvent adsorbed into the pores.

(i) Sihgel@CTMS@GPTMS. Surface functionalization with GPTMS and CTMS was carried out according to a method reported earlier by Renard et al. [61] with some modifications. Typically, $250 \mathrm{mg}$ of dried Sihgel was introduced in $25 \mathrm{~mL}$ toluene together with $175 \mu \mathrm{L}$ CTMS $\left(0.054 \mathrm{M}, \mathrm{CTMS} / \mathrm{SiO}_{2}=0.33\right)$ and $750 \mu \mathrm{L}$ GPTMS $(0.113 \mathrm{M}$, GPTMS $/ \mathrm{SiO}_{2}=0.68$ ). The mixture was maintained under reflux at $100{ }^{\circ} \mathrm{C}$ for $16 \mathrm{~h}$. Reaction was performed in toluene because non-polar solvents have been reported to facilitate aggregation of silane ligands on the silica surface, thus favoring interaction with silanol groups $[48,62]$. The solid was collected by centrifugation, then washed with water and ethanol and finally dried under vacuum conditions at $25^{\circ} \mathrm{C}$ for $10 \mathrm{~h}$. 
GPTMS $/ \mathrm{SiO}_{2}$ molar ratio was varied between 0.34 and 1.5 while $\mathrm{CTMS} / \mathrm{SiO}_{2}$ one was fixed to 0.33 or 0.66 .

(ii) Sihgel@HDTMS@APTMS-GAH. Surface functionalization with APTMS was carried out according to two methods reported earlier on conventional silica by Sorensen et al. [63] and Kao et al. [64] with some modifications. Typically, $250 \mathrm{mg}$ of silicified hydrogel was suspended in $25 \mathrm{~mL}$ of anhydrous toluene, followed by successive addition of $630 \mu \mathrm{L}$ HDTMS $\left(0.055 \mathrm{M}\right.$, HDTMS $\left./ \mathrm{SiO}_{2}=0.33\right)$ and $122 \mu \mathrm{L}$ APTMS $\left(0.027 \mathrm{M}, \mathrm{APTMS} / \mathrm{SiO}_{2}=0.16\right)$. Because of its high degree of hydrophobicity, HDTMS was hydrolyzed first in an oxalic acid solution $(0.1 \mathrm{M}$ oxalic acid) before grafting. After refluxing at $100{ }^{\circ} \mathrm{C}$ for $24 \mathrm{~h}$, the solid denoted Sihgel@HDTMS@APTMS was collected by centrifugation, washed several times with toluene, then dried under vacuum and finally stored under inert $\left(\mathrm{N}_{2}\right)$ atmosphere. Subsequently, $50 \mathrm{mg}$ of the functionalized Sihgel@HDTMS@APTMS material was dispersed in $1.5 \mathrm{~mL}$ acetate buffer ( $\mathrm{pH} 4.6)$ and $77 \mu \mathrm{L}$ glutaraldehyde $(\mathrm{GAH})$ was added $(\mathrm{GAH} / \mathrm{APTMS}=3.1)$. After stirring at room temperature for $10 \mathrm{~h}$, the GAH cross-linked material (denoted Sihgel@HDTMS@APTMS-GAH) was collected by centrifugation, then washed with water and ethanol and finally dried under vacuum conditions at $25^{\circ} \mathrm{C}$ for $10 \mathrm{~h}$.

(iii) Sihgel@CTMS@APTMS-GAH(GAC). Typically, 250 mg silicified hydrogel was suspended in $25 \mathrm{~mL}$ of anhydrous toluene, followed by successive addition of $175 \mu \mathrm{L}$ CTMS (0.054 M, CTMS $\left./ \mathrm{SiO}_{2}=0.33\right)$ and $122 \mu \mathrm{L}$ APTMS $\left(0.027 \mathrm{M}, \mathrm{APTMS} / \mathrm{SiO}_{2}=\right.$ 0.16). After refluxing at $100{ }^{\circ} \mathrm{C}$ for $24 \mathrm{~h}$, the solid denoted Sihgel@CTMS@APTMS was collected by centrifugation, washed several times with toluene, then dried under vacuum and stored under inert $\left(\mathrm{N}_{2}\right)$ atmosphere. Subsequently, $50 \mathrm{mg}$ of the functionalized Sihgel@CTMS@APTMS material was dispersed in $1.5 \mathrm{~mL}$ acetate buffer ( $\mathrm{pH} 4.6$ ) and $77 \mu \mathrm{L}$ of glutaraldehyde $(\mathrm{GAH})$ was added $(\mathrm{GAH} / \mathrm{APTMS}=3.1)$. After stirring at room temperature for $10 \mathrm{~h}$, the GAH cross-linked material (denoted Sihgel@CTMS@APTMS-GAH) was collected by centrifugation, then washed with water and ethanol and finally dried under vacuum conditions at $25^{\circ} \mathrm{C}$ for $10 \mathrm{~h}$. In another synthesis, glutaric anhydride (GAC) was employed as a linker. Typically, $50 \mathrm{mg}$ of Sihgel@CTMS was dispersed in $1.5 \mathrm{~mL}$ DMF, then $50 \mathrm{mg}$.GAC was added $($ GAC/APTMS = 3.2). The mixture was stirred at room temperature for $1 \mathrm{~h}$, then refluxed at $60{ }^{\circ} \mathrm{C}$ for $9 \mathrm{~h}$. The solid was recovered by centrifugation, then washed with water and ethanol and finally dried under vacuum.

In some experiments, for comparison purposes, the Sihgel matrix was silanized with hydrophobic groups from CTMS (Sihgel@CTMS) and HDTMS (Sihgel@HDTMS) taken separately, before considering their combine use (Sihgel@CTMS@HDTMS). A nonhydrophobized surface was also prepared for a control experiment by functionalizing Sihgel with APTMS followed by the activation with GAH (Sihgel@APTMS-GAH). The CTMS $/ \mathrm{SiO}_{2}$ and $\mathrm{HDTMS} / \mathrm{SiO}_{2}$ molar ratio used was 0.33 unless stated otherwise.

\subsection{Immobilization of Lipase B from Candida Antarctica}

For the immobilization of CALB, $2 \mathrm{mg}$ of lipase solubilized in $0.3 \mathrm{~mL}$ buffer solution was added to $20 \mathrm{mg}$ of Sihgel@CTMS@GPTMS dispersed by ultrasound in $1.2 \mathrm{~mL}$ phosphate buffer. Immobilization was carried out at $\mathrm{pH} 7.5$ because the epoxide-ring opening is greatest under near neutral or moderate alkaline conditions [41]. After stirring in an ice bath for $16 \mathrm{~h}$, the supported biocatalyst was collected by centrifugation, washed several times with water and ethanol, then dried under vacuum. The same immobilization procedure was applied on Sihgel@HDTMS@APTMS-GAH and Sihgel@CTMS@APTMS-GAH(GAC) with the only exception that phosphate buffer ( $\mathrm{pH}$ 7.5) was replaced by acetate buffer ( $\mathrm{pH}$ 4.6). In fact, the formation of the imine bond is generally favored near a $\mathrm{pH}$ of 5.0 [42]. In the case where GAC was used as linker, $10 \mathrm{mg}$ of 1-(3-diméthylaminopropyl)-3-éthylcarbodiimide (EDC) were added for carboxylic acid activation in GAC. For comparison purposes, CALB was also anchored by ionic bonding on hydrophobized Sihgel. Typically, $2 \mathrm{mg}$ of CALB was first dissolved in $1.5 \mathrm{~mL}$ acetate buffer solution ( $\mathrm{pH} 4.6$ ), then $20 \mathrm{mg}$ of Sihgel@CTMS 
(or Sihgel@HDTMS) was added. The $\mathrm{pH}$ of reaction medium was chosen between the isoelectric point of CALB (pI 6) and the point of zero charge of silica (PZC 2.0-3.5), so that attractive electrostatic interactions can occur between the support and the enzyme. After stirring in an ice bath for $16 \mathrm{~h}$, the supported biocatalyst was collected by centrifugation, washed with water and ethanol, then dried under vacuum.

\subsection{Characterization Methods}

Attenuated total reflexion Fourier transform infrared (ATR-FTIR) measurements were performed using a MIRacle Diamond prism on a Shimadzu IR Prestidge-21 spectrometer. All spectra were recorded with a resolution of $2 \mathrm{~cm}^{-1}$ in the $4000-400 \mathrm{~cm}^{-1}$ region. Thermogravimetric (TG) analyses were carried out in platinum crucibles using a Setaram TG-DTA 92 microbalance. Samples were analyzed in duplicate. All measurements were performed in air at a flow rate of $20 \mathrm{~mL} / \mathrm{min}$ using a heating ramp of $8{ }^{\circ} \mathrm{C} / \mathrm{min}$, from 40 to $800{ }^{\circ} \mathrm{C}$. The surface coverage of the silanized materials $\left(\mathrm{S}_{\text {cov }}\right)\left(\mathrm{chain} / \mathrm{nm}^{2}\right)$ was determined based on the following equation as described by Chevigny et al. [65]

$$
\mathrm{S}_{\mathrm{cov}}=\left(\frac{\mathrm{S}_{\mathrm{BET}}}{\mathrm{M}_{\mathrm{gr}} \times \mathrm{N}_{\mathrm{A}}}\right) \times\left(\frac{\mathrm{W}_{\mathrm{tot}}-\mathrm{W}_{\mathrm{ref}}}{100-\left(\mathrm{W}_{\mathrm{tot}}-\mathrm{W}_{\mathrm{ref}}\right)}\right)
$$

where $S_{\mathrm{BET}}$ is the specific surface area of the support $\left(\mathrm{nm}^{2} / \mathrm{g}\right), \mathrm{N}_{\mathrm{A}}$ is the Avogadro's constant $\left(6.02 \times 10^{23} / \mathrm{mol}\right), \mathrm{M}_{\mathrm{gr}}$ is the molar weight of the functional group, $\mathrm{W}_{\text {tot }}$ and $\mathrm{W}_{\text {ref }}$ are the weight losses of functionalized silica and bare silica respectively. Nitrogen adsorption-desorption isotherms were collected at $-196{ }^{\circ} \mathrm{C}$ using a Micromeritics Tristar 3020. Typically, prior to analysis, $40-60 \mathrm{mg}$ samples were outgassed at $180{ }^{\circ} \mathrm{C}$ for $16 \mathrm{~h}$ to remove species adsorbed on the surface. The specific surface area $\left(\mathrm{S}_{\mathrm{BET}}\right)$ was calculated from $\mathrm{N}_{2}$-adsorption isotherms using the Brunauer-Emmet-Teller (BET) method. Pore size distributions and pore volumes were determined using the $\mathrm{BJH}$ method assuming a cylindrical pore structure. The maximum grafting density $\left(\mathrm{D}_{\mathrm{g}}{ }^{\max }\right)(\mathrm{mg} / \mathrm{g})$ was determined using the following equation, assuming that a monolayer of silane was formed on the surface of silanized hydrogel [48].

$$
\mathrm{D}_{\mathrm{g}}^{\max }=\left(\frac{\mathrm{S}_{\mathrm{BET}}}{\mathrm{S}_{\mathrm{Si}}}\right)\left(\frac{\mathrm{M}_{\mathrm{W}}}{\mathrm{N}_{\mathrm{A}}}\right)
$$

where $S_{\mathrm{BET}}$ is the specific surface area of the silicified hydrogel $\left(\mathrm{nm}^{2} / \mathrm{g}\right), \mathrm{S}_{\mathrm{Si}}$ is the surface area occupied by a silane ligand $\left(\mathrm{nm}^{2}\right), \mathrm{M}_{\mathrm{W}}$ is the organosilane molecular weight, and $\mathrm{N}_{\mathrm{A}}$ is the Avogadro's constant. Transmission electron microscopy (TEM) images were recorded on a TECNAI microscope operating at $200 \mathrm{kV}$. Powders were deposited directly on a carbon coated copper grid. Scanning electron microscopy (SEM) images were recorded at $3 \mathrm{keV}$ with a FEG Hitachi S-4700 microscope. UV-Visible measurements were carried out using a Perkin Elmer (Lambda 19) spectrophotometer. Enzyme loading in the silicified hydrogel was determined by measuring the initial and final concentration of protein within the immobilization solution using the Bradford method [66]. Calibration curves were established by measuring the ratio between the absorbance at $595 \mathrm{~nm}$ corresponding to the anionic blue form of the Coomassie Brilliant Blue G-250 binding to the protein, and the absorbance at $450 \mathrm{~nm}$ corresponding to the cationic red form of the dye. The immobilization efficiency (\%) and the loading capacity (wt. \%) were deduced by mass balance using the following equations [67]:

$$
\begin{gathered}
\text { Immobilization efficiency }=\frac{\left(\mathrm{m}-\mathrm{C}_{1} \mathrm{~V}_{1}\right)}{\mathrm{m}} \times 100 \\
\text { Loading capacity }=\frac{\left(\mathrm{m}-\mathrm{C}_{1} \mathrm{~V}_{1}\right)}{\mathrm{Ws}} \times 100
\end{gathered}
$$


where $\mathrm{m}(\mathrm{mg})$ is the mass of the enzyme added to the immobilization solution, $\mathrm{C}_{1}(\mathrm{mg} / \mathrm{mL})$ and $V_{1}(\mathrm{~mL})$ are the concentration of enzyme in the supernatant and its volume respectively, and Ws $(\mathrm{g})$ is the weight of the support. Polarized optical microscopy images were recorded on an Olympus (BX51) microscope. Viscosity measurements were carried out at $25^{\circ} \mathrm{C}$ using a viscosimeter from Brookfield equipped with a cylindrical geometry (module SC4-18). The apparent viscosity vs. shear-rate plots were recorded in a $0.1-500 \mathrm{~s}^{-1}$ range of shear-rate. Dynamic light scattering (DLS) and Zeta potential measurements were performed at $25^{\circ} \mathrm{C}$ using the Malvern Zeta Nanosizer Instrument equipped with a $4.0 \mathrm{~mW}$ He-Ne red laser operating at $633 \mathrm{~nm}$. Detection was carried out in backscattering mode (scattering angle $173^{\circ}$ ) with respect to the incident beam. Each sample was analyzed three times with an average of ten runs per measurement.

\subsection{Activity Measurements}

Free CALB used in this study had a hydrolytic activity of $9 \mathrm{U} / \mathrm{mg}$. One lipase unit corresponds to the amount of enzyme releasing $1 \mu \mathrm{mol}$ of butyric acid per minute at $40{ }^{\circ} \mathrm{C}$ ( $\mathrm{pH}$ 8.0) using tributyrin as substrate. The catalytic performance of immobilized lipase was evaluated in the oxidation of DFF to FDCA as reported by Qin et al. [68], with some modifications. Typically, DFF (2.48 mg, $10 \mathrm{mM})$ was dissolved in $2 \mathrm{~mL}$ of a mixture of ethyl acetate (EtOAc) and tert-butanol $(\mathrm{t}-\mathrm{BuOH})(1: 1 \mathrm{v} / \mathrm{v})$, to which 2.0 equivalents of aqueous $\mathrm{H}_{2} \mathrm{O}_{2}(4.5 \mu \mathrm{L}, 30 \% \mathrm{v} / \mathrm{v})$ were added. The reaction was started with addition of $2 \mathrm{mg}$ of CALB and maintained under stirring in a thermostatic bath at $40^{\circ} \mathrm{C}$. About 2.0 equivalents $\mathrm{H}_{2} \mathrm{O}_{2}$ aliquots were added regularly every hour, up to $7 \mathrm{~h}$ of reaction time. The analysis of DFF and its oxidation products (FDCA and FFCA) was carried out using ${ }^{1} \mathrm{H}$ nuclear magnetic resonance $\left({ }^{1} \mathrm{H}\right.$ NMR) spectroscopy and high liquid performance chromatography (HPLC). ${ }^{1} \mathrm{H}$ NMR spectra were recorded on a BRUKER DPX300 Avance spectrometer operating at $300 \mathrm{MHz}$ at $25^{\circ} \mathrm{C}$ with 16 scans per measurement. Prior to analysis, products were dissolved in $600 \mu \mathrm{L}$ DMSO. Typical profiles of the ${ }^{1} \mathrm{H}$ NMR spectra of isolated products and reaction mixture are shown in Figure S4. DFF conversion (\%) together with the FFCA and FDCA yields (\%) was calculated according to the following equations:

$$
\begin{gathered}
\text { DFF Conversion }=100-\left(\frac{\mathrm{A}_{\mathrm{DFF}} / 2}{\mathrm{~A}_{\mathrm{FDCA}} / 2+\mathrm{A}_{\mathrm{FFCA}}+\mathrm{A}_{\mathrm{DFF}} / 2} \times 100\right) \\
\text { FFCA yield }=\frac{\mathrm{A}_{\mathrm{FFCA}}}{\mathrm{A}_{\mathrm{FDCA}} / 2+\mathrm{A}_{\mathrm{FFCA}}+\mathrm{A}_{\mathrm{DFF}} / 2} \times 100 \\
\text { FDCA yield }=\frac{\mathrm{A}_{\mathrm{FDCA}} / 2}{\mathrm{~A}_{\mathrm{FDCA}} / 2+\mathrm{A}_{\mathrm{FFCA}}+\mathrm{A}_{\mathrm{DFF}} / 2} \times 100
\end{gathered}
$$

where $A_{F D C A}, A_{F F C A}$, and $A_{D F F}$ are the integrated areas of peak a: $\delta=7.30 \mathrm{ppm}(\mathrm{s}, 2 \mathrm{H}, \mathrm{Ar})$ from FDCA, peak b: $\delta=7.60$ ppm $(\mathrm{d}, 1 \mathrm{H}, \mathrm{Ar})$ from FFCA and peak a: $\delta=7.67 \mathrm{ppm}(\mathrm{s}, 2 \mathrm{H}$, Ar) from DFF, respectively. The factor 2 derives from the two protons on the furan ring of FDCA and DFF, whereas only one proton is available on the furan ring of FFCA. HPLC analyses were performed on a Perkin Elmer Flexar apparatus using an Aminex HPX-87H (300 mm length $\times 7.8 \mathrm{~mm}$ diameter) column heated at $60^{\circ} \mathrm{C}$. The mobile phase was acetic acid $(0.2 \%)$ at a flow rate of $0.6 \mathrm{~mL} / \mathrm{min}$. Aliquots of $1 \mu \mathrm{L}$ of each sample were injected and analyzed at a wavelength of $284 \mathrm{~nm}$ using a photodiode array detector. Standard calibration curves were used to determine the amounts of DFF, FFCA, and FDCA. HPLC calibration curves and typical chromatograms of the isolated products and reaction mixture are shown in Figures S5 and S6.

Supplementary Materials: The following are available online at https:/ /www.mdpi.com/article/10 $.3390 /$ gels8010003/s1. Figure S1: (A) Viscosity vs. shear-rate curves for different mixtures prepared with $100 \mathrm{mg} / \mathrm{mL} \alpha-C D$ and increasing concentrations of pluronic F127: (a) $8 \mathrm{mg} / \mathrm{mL}$, (b) $16 \mathrm{mg} / \mathrm{mL}$ and (c) $30 \mathrm{mg} / \mathrm{mL}$. All measurements were performed at $25^{\circ} \mathrm{C}$. (B) Visual aspect of the supramolecular F127/ $\alpha$-CD hydrogel (16 mg/mL F127) before and after shaking. Figure S2: ${ }^{1} \mathrm{H}$ NMR $(300 \mathrm{MHz}$, 
DMSO-D6) spectrum of the reaction products obtained on DFF oxidation catalyzed by the supernatant recovered after the first run with the Sihgel@CTMS@APTMS-GAH@CALB2 biocatalyst. Reaction conditions: $10 \mathrm{mM} \mathrm{DFF}, 2 \mathrm{~mL} \mathrm{EtOAc/tBuOH}(1: 1 . v / v)$, sequential addition of 2.0 equivalents aqueous $\mathrm{H}_{2} \mathrm{O}_{2}(30 \% \mathrm{v} / \mathrm{v})$ every hour for $7 \mathrm{~h}$, temperature $40{ }^{\circ} \mathrm{C}$, reaction time $24 \mathrm{~h}$. Figure S3: ${ }^{1} \mathrm{H}$ NMR (300MHz, $\left.\mathrm{D}_{2} \mathrm{O}\right)(\mathrm{A})$ and ${ }^{13} \mathrm{C}$ NMR $\left(\mathrm{D}_{2} \mathrm{O}, 12,000\right.$ accumulations) (B) spectra of cationic crosslinked $\beta$-cyclodextrin (CCL $\beta$-CD). The signal at $3.16 \mathrm{ppm}$ in $(\mathrm{A})$ is characteristic of the methyl protons from trimethylammonium groups. The resonance a in (B) is typical of $\mathrm{C} 7, \mathrm{C} 8, \mathrm{C} 7^{\prime}, \mathrm{C} 8^{\prime}$, and $\mathrm{C} 9^{\prime}$ from the 2-hydroxypropyl ether segments. Resonances C8" and C9" indicate also the presence of glycidyl group which may be responsible for gelation of CCL $\beta-C D$ after prolonged storage. Figure S4: ${ }^{1} \mathrm{H}$ NMR (300MHz, DMSO-D6) spectra of (a) DFF a: $\delta=7.67$ (s, 2H, Ar), b: $\delta=9.82$ (s, 2H, aldehyde); (b) FFCA a: $\delta=7.39(\mathrm{~d}, 1 \mathrm{H}, \mathrm{Ar}), \mathrm{b}: \delta=7.60(\mathrm{~d}, 1 \mathrm{H}, \mathrm{Ar}), \mathrm{c}: \delta=9.73$ (s, 1H, aldehyde); (c) FDCA a: $\delta$ $=7.30$ (s, 2H, Ar); (d) Typical spectrum of reaction products obtained with Sihgel@CTMS@APTMSGAH@CALB2: DFF conversion 100\%; FFCA yield 10\% and FDCA yield 90\%. Figure S5: HPLC chromatograms of standard solutions: (a) DFF; (b) FFCA; (c) FDCA and (d) typical spectrum of the reaction mixture. Analytical conditions: mobile phase acetic acid $(0.2 \%)$, temperature $60{ }^{\circ} \mathrm{C}$, flow rate $0.6 \mathrm{~mL} / \mathrm{min}$. UV detection at $284 \mathrm{~nm}$. Figure S6: HPLC calibration curves of (a) DFF, (b) FFCA and (c) FDCA. The analytical conditions were the same as those described in Figure S5.

Author Contributions: The manuscript was written through contributions of all authors. R.B. supervised the project and wrote the paper. C.D. prepared and characterized all catalysts and performed the catalytic tests. A.P. and E.M. contributed in reviewing and editing of the manuscript. All authors discussed the results and commented on the manuscript. All authors have read and agreed to the published version of the manuscript.

Funding: This research was funded by Région Hauts-de-France and the University of Artois, as well as Chevreul Institute (FR 2638), Ministère de l'Enseignement Supérieur, de la Recherche et de l'Innovation and FEDER.

Institutional Review Board Statement: Not applicable.

Informed Consent Statement: Not applicable.

Data Availability Statement: Not applicable.

Acknowledgments: Chevreul Institute (FR 2638), Ministère de 1'Enseignement Supérieur, de la Recherche et de l'Innovation and FEDER are acknowledged for supporting and funding this work. C.D. is grateful to the Région Hauts-de-France and the University of Artois who funded his PhD grant. We are grateful to D. Prevost, J. Ternel, N. Kania and A. Addad for technical assistance with the reactor setup, NMR, TG analysis and electronic microscopy respectively. The TEM facility in Lille is supported by the Conseil Regional des Hauts-de-France and the European Regional Development Fund (ERDF).

Conflicts of Interest: The authors declare no conflict of interest. The funders had no role in the design of the study; in the collection, analyses, or interpretation of data; in the writing of the manuscript; or in the decision to publish the results.

\section{Abbreviations}

$\begin{array}{ll}\text { CD } & \text { Cyclodextrin } \\ \text { Pluronic F127 } & \text { PEO }_{100} \mathrm{PPO}_{70} \mathrm{PEO}_{100} \mathrm{PEO} \text { : poly(ethylene oxide) and PPO: poly(propylene oxide) } \\ \text { CALB } & \text { Lipase B from Candida antarctica } \\ \text { TMOS } & \text { Tetramethyl orthosilicate } \\ \text { CTMS } & \text { Chlorotrimethylsilane } \\ \text { HDTMS } & \text { Hexadecyltrimethoxysilane } \\ \text { APTMS } & \text { (3-aminopropyl)-trimethoxysilane } \\ \text { GPTMS } & \text { (3-Glycidyloxypropyl)trimethoxysilane } \\ \text { GAH } & \text { Glutaraldehyde } \\ \text { GAC } & \text { Glutaric anhydride } \\ \text { EDC } & \text { N-(3-Dimethylaminopropyl)-N'-ethylcarbodiimide hydrochloride } \\ \text { CCL } \beta-C D & \text { Cationic cross-linked } \beta-C D\end{array}$




$\begin{array}{ll}\text { EP } & \text { Epichlorohydrin } \\ \text { GTMAC } & \text { Glycidyltrimethylammonium chloride } \\ \text { DFF } & \text { 2,5-diformylfuran } \\ \text { FDCA } & \text { 2,5-furandicarboxylic acid } \\ \text { FFCA } & \text { 5-formylfuran-2-carboxylic acid } \\ \text { DLS } & \text { Dynamic Light Scattering } \\ \text { S }_{\text {BET }} & \text { Surface area determined by the Brunauer, Emmett and Teller method } \\ \text { BJH } & \text { Barrett, Joyner and Halenda } \\ \text { TEM } & \text { Transmission Electron Microscopy } \\ \text { SEM } & \text { Scanning Electron Microscopy } \\ \text { NMR } & \text { Nuclear Magnetic Resonance } \\ \text { HPLC } & \text { High Performance Liquid Chromatography } \\ \text { ATR-FTIR } & \text { Attenuated Total Reflexion Fourier Transform Infrared spectroscopy } \\ \text { TGA } & \text { Thermogravimetric analysis } \\ D_{g} & \text { Grafting density } \\ D_{g} \text { max } & \text { Maximum grafting density } \\ S_{\text {cov }} & \text { Surface coverage }\end{array}$

\section{References}

1. Blettler, M.C.; Abrial, E.; Khan, F.R.; Sivri, N.; Espinola, L.A. Freshwater plastic pollution: Recognizing research biases and identifying knowledge gaps. Water Res. 2018, 143, 416-424. [CrossRef] [PubMed]

2. Gallezot, P. Conversion of biomass to selected chemical products. Chem. Soc. Rev. 2012, 41, 1538-1558. [CrossRef] [PubMed]

3. Gross, R.A.; Kalra, B. Biodegradable Polymers for the Environment. Science 2002, 297, 803-807. [CrossRef] [PubMed]

4. Binder, J.B.; Raines, R. Simple Chemical Transformation of Lignocellulosic Biomass into Furans for Fuels and Chemicals. J. Am. Chem. Soc. 2009, 131, 1979-1985. [CrossRef] [PubMed]

5. Cho, E.J.; Trinh, L.T.P.; Song, Y.; Lee, Y.G.; Bae, H.-J. Bioconversion of biomass waste into high value chemicals. Bioresour. Technol. 2019, 298, 122386. [CrossRef]

6. European-Bioplastics. Available online: https://www.european-bioplastics.org/market/ (accessed on 7 October 2021).

7. Sheldon, R.A. Green and sustainable manufacture of chemicals from biomass: State of the art. Green Chem. 2013, 16, 950-963. [CrossRef]

8. Zhang, Z.; Deng, K. Recent Advances in the Catalytic Synthesis of 2,5-Furandicarboxylic Acid and Its Derivatives. ACS Catal 2015, 5, 6529-6544. [CrossRef]

9. Motagamwala, A.H.; Won, W.; Sener, C.; Alonso, D.M.; Maravelias, C.T.; Dumesic, J.A. Toward biomass-derived renewable plastics: Production of 2,5-furandicarboxylic acid from fructose. Sci. Adv. 2018, 4, eaap9722. [CrossRef]

10. Sheldon, R.A.; van Pelt, S. Enzyme immobilisation in biocatalysis: Why, what and how. Chem. Soc. Rev. 2013, 42, 6223-6235. [CrossRef]

11. Tao, J.; Kazlaukas, R.J. Biocatalysis for Green Chemistry and Chemical Process Development; Wiley: Hoboken, NJ, USA, 2011.

12. Wohlgemuth, R. Biocatalysis-Key to sustainable industrial chemistry. Curr. Opin. Biotechnol. 2010, 21, 713-724. [CrossRef]

13. Shoda, S.-I.; Uyama, H.; Kadokawa, J.-I.; Kimura, S.; Kobayashi, S. Enzymes as Green Catalysts for Precision Macromolecular Synthesis. Chem. Rev. 2016, 116, 2307-2413. [CrossRef] [PubMed]

14. Bommarius, A.S.; Paye, M.F. Stabilizing biocatalysts. Chem. Soc. Rev. 2013, 42, 6534-6565. [CrossRef] [PubMed]

15. Chapman, J.; Ismail, A.E.; Dinu, C.Z. Industrial Applications of Enzymes: Recent Advances, Techniques, and Outlooks. Catalysts 2018, 8, 238. [CrossRef]

16. Roy, I.; Prasad, S. Converting enzymes into tools of industrial importance. Recent Pat. Biotechnol. 2017, 12, 33-56.

17. Kishida, A.; Ikada, Y. Polymeric Biomaterials; Dumitriu, S., Ed.; Marcel Dekker: New York, NY, USA, 2002.

18. Rosiak, J.M.; Yoshii, F. Hydrogels and their medical applications. Nucl. Instrum. Methods Phys. Res. B 1999, 151, 56-64. [CrossRef]

19. Wang, D.; Tong, G.; Dong, R.; Zhou, Y.; Shen, J.; Zhu, X. Self-assembly of supramolecularly engineered polymers and their biomedical applications. Chem. Commun. 2014, 50, 11994-12017. [CrossRef]

20. Li, J.; Harada, A.; Kamachi, M. Sol-Gel Transition during Inclusion Complex Formation between $\alpha$-Cyclodextrin and High Molecular Weight Poly(ethylene glycol)s in Aqueous Solution. Polym. J. 1994, 26, 1019-1026. [CrossRef]

21. Ceccato, M.; Nostro, P.L.; Rossi, C.; Bonechi, C.; Donati, A.A.; Baglioni, P. Molecular Dynamics of Novel $\alpha$-Cyclodextrin Adducts Studied by 13C-NMR Relaxation. J. Phys. Chem. B 1997, 101, 5094-5099. [CrossRef]

22. Harada, A.; Hashidzume, A.; Yamaguchi, H.; Takashima, Y. Polymeric Rotaxanes. Chem. Rev. 2009, 109, 5974-6023. [CrossRef]

23. Travelet, C.; Schlatter, G.; Hébraud, P.; Brochon, C.; Lapp, A.; Hadziioannou, G. Formation and self-organization kinetics of $\alpha$-CD/PEO-based pseudo-polyrotaxanes in water. A specific behavior at $30^{\circ} \mathrm{C}$. Langmuir 2009, 25, 8723-8734. [CrossRef]

24. Travelet, C.; Hébraud, P.; Perry, C.; Brochon, C.; Hadziioannou, G.; Lapp, A.; Schlatter, G. Temperature-Dependent Structure of $\alpha-$ CD/PEO-Based Polyrotaxanes in Concentrated Solution in DMSO: Kinetics and Multiblock Copolymer Behavior. Macromolecules 2010, 43, 1915-1921. [CrossRef] 
25. Drury, J.L.; Mooney, D.J. Hydrogels for tissue engineering: Scaffold design variables and applications. Biomaterials 2003, 24, 4337-4351. [CrossRef]

26. Vermonden, T.; Censi, R.; Hennink, W.E. Hydrogels for Protein Delivery. Chem. Rev. 2012, 112, 2853-2888. [CrossRef]

27. Biswas, S.; Ghosh, T.; Kori, D.K.K.; Das, A.K. Bicomponent Coassembled Hydrogel as a Template for Selective Enzymatic Generation of DOPA. Langmuir 2021, 37, 10883-10889. [CrossRef] [PubMed]

28. Li, J.; Loh, X.J. Cyclodextrin-based supramolecular architectures: Syntheses, structures, and applications for drug and gene delivery. Adv. Drug Deliv. Rev. 2008, 60, 1000-1017. [CrossRef] [PubMed]

29. Wang, Q.; Yang, Z.; Wang, L.; Ma, M.; Xu, B. Molecular hydrogel-immobilized enzymes exhibit superactivity and high stability in organic solvents. Chem. Commun. 2007, 1032-1034. [CrossRef] [PubMed]

30. Bleta, R.; Menuel, S.; Léger, B.; Da Costa, A.; Monflier, E.; Ponchel, A. Evidence for the existence of crosslinked crystalline domains within cyclodextrin-based supramolecular hydrogels through sol-gel replication. RSC Adv. 2014, 4, 8200-8208. [CrossRef]

31. Decarpigny, C.; Bleta, R.; Ponchel, A.; Monflier, E. Confinement of Candida Antarctica Lipase B in a Multifunctional CyclodextrinDerived Silicified Hydrogel and Its Application as Enzymatic Nanoreactor. ACS Appl. Bio Mater. 2019, 2, 5568-5581. [CrossRef]

32. Díaz, J.F.; Balkus, K.J., Jr. Enzyme immobilization in MCM-41 molecular sieve. J. Molecul. Catal. B Enzym. 1996, 2, 115-126. [CrossRef]

33. Yiu, H.H.; A Wright, P.; Botting, N.P. Enzyme immobilisation using SBA-15 mesoporous molecular sieves with functionalised surfaces. J. Mol. Catal. B Enzym. 2001, 15, 81-92. [CrossRef]

34. Luckarift, H.R.; Spain, J.C.; Naik, R.R.; O Stone, M. Enzyme immobilization in a biomimetic silica support. Nat. Biotechnol. 2004, 22, 211-213. [CrossRef]

35. Küchler, A.; Yoshimoto, M.; Luginbühl, S.; Mavelli, F.; Walde, P. Enzymatic reactions in confined environments. Nat. Nanotechnol. 2016, 11, 409-420. [CrossRef] [PubMed]

36. Basso, A.; Serban, S. Industrial applications of immobilized enzymes-A review. Mol. Catal. 2019, 479, 110607. [CrossRef]

37. Anderson, E.M.; Larsson, K.M.; Kirk, O. One Biocatalyst-Many Applications: The Use of Candida Antarctica B-Lipase in Organic Synthesis. Biocatal. Biotransform. 1998, 16, 181-204. [CrossRef]

38. Tzialla, A.A.; Pavlidis, I.; Felicissimo, M.P.; Rudolf, P.; Gournis, D.; Stamatis, H. Lipase immobilization on smectite nanoclays: Characterization and application to the epoxidation of $\alpha$-pinene. Bioresour. Technol. 2010, 101, 1587-1594. [CrossRef]

39. Hernandez, K.; Fernandez-Lafuente, R. Lipase B from Candida antarctica immobilized on octadecyl Sepabeads: A very stable biocatalyst in the presence of hydrogen peroxide. Process. Biochem. 2011, 46, 873-878. [CrossRef]

40. Mateo, C.; Fernández-Lorente, G.; Abian, O.; Fernández-Lafuente, R.; Guisán, J.M. Multifunctional Epoxy Supports: A New Tool To Improve the Covalent Immobilization of Proteins. The Promotion of Physical Adsorptions of Proteins on the Supports before Their Covalent Linkage. Biomacromolecules 2000, 1, 739-745. [CrossRef]

41. Barbosa, O.; Torres, R.T.R.; Ortiz, C.; Berenguer-Murcia, Á; Rodrigues, R.C.; Fernandez-Lafuente, R. Heterofunctional Supports in Enzyme Immobilization: From Traditional Immobilization Protocols to Opportunities in Tuning Enzyme Properties. Biomacromolecules 2013, 14, 2433-2462. [CrossRef]

42. Graham Solomons, T.W. Fundamentals of Organic Chemistry; Wiley: Hoboken, NJ, USA, 1997; pp. $684-685$.

43. Vansant, E.F.; Van Der Voort, P.; Vrancken, K.C. Characterization and Chemical Modification of the Silica Surface; Elsevier: Amsterdam, The Netherlands, 1995.

44. Grube, M.; Bekers, M.; Upite, D.; Kaminska, E. Infrared spectra of some fructans. Spectroscopy 2002, 16, 289-296. [CrossRef]

45. Hruby, S.L.; Shanks, B.H. Acid-base cooperativity in condensation reactions with functionalized mesoporous silica catalysts. J. Catal. 2009, 263, 181-188. [CrossRef]

46. Shukla, D.; Kasisomayajula, S.; Parameswaran, V. Epoxy composites using functionalized alumina platelets as reinforcements. Compos. Sci. Technol. 2008, 68, 3055-3063. [CrossRef]

47. Zhao, X.S.; Lu, G. Modification of MCM-41 by Surface Silylation with Trimethylchlorosilane and Adsorption Study. J. Phys. Chem. $B$ 1998, 102, 1556-1561. [CrossRef]

48. Liu, Y.; Li, Y.; Li, X.-M.; He, T. Kinetics of (3-Aminopropyl)triethoxylsilane (APTES) Silanization of Superparamagnetic Iron Oxide Nanoparticles. Langmuir 2013, 29, 15275-15282. [CrossRef] [PubMed]

49. Mijovic, J.; Fishbain, A.; Wijaya, J. Mechanistic modeling of epoxy-amine kinetics. 1. Model compound study. Macromolecules 1992, 25, 979-985. [CrossRef]

50. Ke, Q.; Fu, W.; Wang, S.; Tang, T.; Zhang, J. Facile Preparation of Superhydrophobic Biomimetic Surface Based on Octadecyltrichlorosilane and Silica Nanoparticles. ACS Appl. Mater. Interfaces 2010, 2, 2393-2398. [CrossRef] [PubMed]

51. Krystof, M.; Pérez-Sánchez, M.; de María, P.D. Lipase-Mediated Selective Oxidation of Furfural and 5-Hydroxymethylfurfural. ChemSusChem 2013, 6, 826-830. [CrossRef]

52. Zhao, Y.; Ma, C.-Y.; Yuen, A.S.-N.; Phillips, D.L. Study of Succinylated Food Proteins by Raman Spectroscopy. J. Agric. Food Chem. 2004, 52, 1815-1823. [CrossRef]

53. Karich, A.; Kleeberg, S.B.; Ullrich, R.; Hofrichter, M. Enzymatic preparation of 2,5-furandicarboxylic acid (FDCA)-A substitute of terephthalic acid by the joined action of three fungal enzymes. Microorganisms 2018, 6, 5. [CrossRef]

54. Junthip, J.; Tabary, N.; Leclercq, L.; Martel, B. Cationic $\beta$-cyclodextrin polymer applied to a dual cyclodextrin polyelectrolyte multilayer system. Carbohydr. Polym. 2015, 126, 156-167. [CrossRef] 
55. Renard, E.; Deratani, A.; Volet, G.; Sebille, B. Preparation and characterization of water soluble high molecular weight $\beta$ cyclodextrin-epichlorohydrin polymers. Eur. Polym. J. 1997, 33, 49-57. [CrossRef]

56. Morin-Crini, N.; Crini, G. Environmental applications of water-insoluble $\beta$-cyclodextrin-epichlorohydrin polymers. Prog. Polym. Sci. 2013, 38, 344-368. [CrossRef]

57. Cryan, S.A.; Holohan, A.; Donohue, R.; Darcy, R.; O'Driscoll, C.M. Celltransfection with polycationic cyclodextrin vectors. Eur. J. Pharm. Sci. 2004, 21, 625-633. [CrossRef]

58. Noël, S.; Bourbiaux, D.; Tabary, N.; Ponchel, A.; Martel, B.; Monflier, E.; Léger, B. Acid-tolerant cyclodextrin-based ruthenium nanoparticles for the hydrogenation of unsaturated compounds in water. Catal. Sci. Technol. 2017, 7, 5982-5992. [CrossRef]

59. Kundys, A.; Białecka-Florjańczyk, E.; Fabiszewska, A.; Małajowicz, J. Candida antarctica Lipase B as Catalyst for Cyclic Esters Synthesis, Their Polymerization and Degradation of Aliphatic Polyesters. J. Polym. Environ. 2017, 26, 396-407. [CrossRef]

60. Uppenberg, J.; Oehrner, N.; Norin, M.; Hult, K.; Kleywegt, G.J.; Patkar, S.; Waagen, V.; Anthonsen, T.; Jones, T.A. Crystallographic and molecular-modeling studies of lipase B from Candida antarctica reveal a stereospecificity pocket for secondary alcohols. Biochemistry 1995, 34, 16838-16851. [CrossRef] [PubMed]

61. Renard, G.; Mihaela, M.; Galarneau, A.; Lerner, D.A.; Brunel, D. Immobilisation of a biological chelate in porous mesostructured silica for selective metal removal from wastewater and its recovery. New J. Chem. 2005, 29, 912-918. [CrossRef]

62. Sharma, K.K.; Asefa, T. Efficient Bifunctional Nanocatalysts by Simple Postgrafting of Spatially Isolated Catalytic Groups on Mesoporous Materials. Angew. Chem. Int. Ed. 2007, 46, 2879-2882. [CrossRef]

63. Sörensen, M.H.; Ng, J.B.S.; Bergström, L.; Alberius, P.C.A. Improved enzymatic activity of Thermomyces lanuginosus lipase immobilized in a hydrophobic particulate mesoporous carrier. J. Colloid Interface Sci. 2010, 343, 359-365. [CrossRef]

64. Kao, K.-C.; Lee, C.-H.; Lin, T.-S.; Mou, C.-Y. Cytochrome c covalently immobilized on mesoporous silicas as a peroxidase: Orientation effect. J. Mater. Chem. 2010, 20, 4653-4662. [CrossRef]

65. Chevigny, C.; Gigmes, D.; Bertin, D.; Jestin, J.; Boué, F. Polystyrene grafting from silica nanoparticles via nitroxide-mediated polymerization (NMP): Synthesis and SANS analysis with the contrast variation method. Soft Matter 2009, 5, 3741-3753. [CrossRef]

66. Bradford, M.M. A rapid and sensitive method for the quantitation of microgram quantities of protein utilizing the principle of protein-dye binding. Anal. Biochem. 1976, 72, 248-254. [CrossRef]

67. Cui, J.; Feng, Y.; Lin, T.; Tan, Z.; Zhong, C.; Jia, S. Mesoporous Metal-Organic Framework with Well-Defined Cruciate Flower-Like Morphology for Enzyme Immobilization. ACS Appl. Mater. Interfaces 2017, 9, 10587-10594. [CrossRef] [PubMed]

68. Qin, Y.-Z.; Li, Y.-M.; Zong, M.-H.; Wu, H.; Li, N. Enzyme-catalyzed selective oxidation of 5-hydroxymethylfurfural (HMF) and separation of HMF and 2,5-diformylfuran using deep eutectic solvents. Green Chem. 2015, 17, 3718-3722. [CrossRef] 